\title{
Detection of QTLs for seedling characteristics in barley (Hordeum vulgare L.) grown under hydroponic culture condition
}

\author{
Qifei Wang ${ }^{1}$, Genlou Sun ${ }^{1,2}$, Xifeng Ren ${ }^{1}$, Jibin Wang ${ }^{1}$, Binbin Du', Chengdao Li ${ }^{3}$ and Dongfa Sun ${ }^{1,4^{*}}$ (D)
}

\begin{abstract}
Background: Seedling characteristics play significant roles in the growth and development of barley (Hordeum vulgare L.), including stable stand establishment, water and nutrients uptake, biotic resistance and abiotic stresses, and can influence yield and quality. However, the genetic mechanisms underlying seedling characteristics in barley are largely unknown and little research has been done. In the present work, 21 seedling-related characteristics are assessed in a barley double haploid (DH) population, grown under hydroponic conditions. Of them, leaf age (LAG), shoot height (SH), maximum root length (MRL), main root number (MRN) and seedling fresh weight (SFW) were investigated at the 13th, 20th, 27th, and 34th day after germination. The objectives were to identify quantitative trait loci (QTLS) underlying these seedling characteristics using a high-density linkage map and to reveal the QTL expression pattern by comparing the QTLs among four different seedling growth stages.

Results: A total of 70 QTLs were distributed over all chromosomes except 4H, and, individually, accounted for 5.01\%-77. 78\% of phenotypic variation. Out of the 70 detected QTLs, 23 showed a major effect on 14 seedling-related characteristics. Ten co-localized chromosomal regions on 2H (five regions), 3H (two regions) and 7H (three regions) involved $39 \mathrm{QTLs}$ (55. $71 \%)$, each simultaneously influenced more than one trait. Meanwhile, 9 co-localized genomic regions involving 22 QTLs for five seedling characteristics (LAG, SH, MRL, MRN and SFW) at the 13th, 20th, 27th and 34th day-old seedling were common for two or more growth stages of seedling. QTL in the vicinity of Vrs 1 locus on chromosome $2 \mathrm{H}$ with the favorable alleles from Huadamai 6 was found to have the largest main effects on multiple seedling-related traits.

Conclusions: Six QTL cluster regions associated with 16 seedling-related characteristics were observed on chromosome $2 \mathrm{H}, 3 \mathrm{H}$ and $7 \mathrm{H}$. The majority of the 29 regions identified for five seedling characteristics were selectively expressed at different developmental stages. The genetic effects of 9 consecutive expression regions displayed different developmental influences at different developmental stages. These findings enhanced our understanding of a genetic basis underlying seedling characteristics in barley. Some QTLs detected here could be used for marker-assisted selection (MAS) in barley breeding.
\end{abstract}

Keywords: Barley (Hordeum vulgare L.), Seedling characteristics, Hydroponic culture, Quantitative trait loci (QTL), Dynamic QTL

\footnotetext{
* Correspondence: sundongfa1@mail.hzau.edu.cn

${ }^{1}$ College of Plant Science and Technology, Huazhong Agricultural University,

Wuhan 430070, China

${ }^{4}$ Hubei Collaborative Innovation Center for Grain Industry, Jingzhou, Hubei

434025, China

Full list of author information is available at the end of the article
}

(c) The Author(s). 2017 Open Access This article is distributed under the terms of the Creative Commons Attribution 4.0 International License (http://creativecommons.org/licenses/by/4.0/), which permits unrestricted use, distribution, and reproduction in any medium, provided you give appropriate credit to the original author(s) and the source, provide a link to the Creative Commons license, and indicate if changes were made. The Creative Commons Public Domain Dedication waiver (http://creativecommons.org/publicdomain/zero/1.0/) applies to the data made available in this article, unless otherwise stated. 


\section{Background}

As the earliest domesticated crop and the fourth most important cereal crop in the world, barley (Hordeum vulgare L.) is not only widely used as human food and animal feed, but is also an ideal model of genetic research because it is early maturing, diploid, self- fertilizing and has a short growth period [1-3]. However, its growth and production are also greatly affected by seedling characteristics. The seedling stage (from seedling emergence to jointing) is considered as the most critical stage for barley production, and plays significant role in barley growth and development, including stable stand establishment, water and nutrients uptake, biotic resistance and abiotic stresses, and can influence yield and quality $[4,5]$. In fact, strong seedling vigor and rapid seedling growth are important breeding targets in barley, as well as in other crops [6-8]. Seedling vigor has been identified to be associated with salt tolerance [9], drought tolerance [10, 11], nutrient uptake [12], weed competitiveness [8] and yield [13, 14]. It is difficult to assess seedling characteristics because a majority of important seedling characteristics are complex, quantitative traits determined by an array of developmental processes, genetic and environmental factors. The genetic mechanisms controlling seedling characteristics in barley are poorly known and little research has been done in this regard. Genetic variation for seedling characteristics in barley varieties does exist, and dissecting the genetic and molecular basis of seedling characteristics is necessary for genetic improvement of barley cultivars to enhance seedling vigor.

The information on the genetic basis underlying seedling characteristics, especially for root characteristics, is limited because it is difficult to obtain reliable phenotypic data in a large number of seedlings and in a complex external environment. It is also difficult to continuously measure these traits from the same seedling due to destruction of the seedlings in field experiments [15-17]. Therefore, an alternative approach is to examine seedling characteristics under controlled conditions using hydroponic culture, which has several advantages over field and other conventional techniques, including: (i) ease of investigation of seedling characteristics (as compared with field experiment), (ii) exclusion of soil and environment interference to increase measurement repeatability, (iii) investigation of large numbers of lines in short period of time, and (iv) precise control of the concentration of nutrient concentration [18]. At present, this method has been widely used in rice [19-21], maize [15, 22, 23] and wheat $[16,24,25]$, and many QTLs have been detected at various water and nutrient regimes. Some researchers have used this method to identify QTLs associated with salt tolerance $[3,26]$, waterlogging tolerance [27-29] and nitrogen stress tolerance [30] in barley.
With the development of molecular markers and continuous encryption of genetic map, QTL analysis has become a powerful tool to dissect complex traits and identify chromosomal regions harboring genes that control these quantitative traits [31,32], and has been extensively used for genetic dissection of important traits in barley [33-35]. The QTLs underlying yield [34, 36, 37] and quality $[35,38,39]$ traits at later growth stages have been characterized previously, and the QTLs for seedling characteristics reported were mainly identified under salt tolerance $[29,40,41]$, waterlogging tolerance [29, 42], drought tolerance [43] and nitrogen stress tolerance [30], while seedling characteristics related to grain yield and quality at early developmental stages are not well investigated.

The objectives of our study were to identify QTLs underlying seedling characteristics in hydroponics at seedling growth stages, and compare its QTL expression patterns among four different seedling growth stages.

\section{Results}

\section{Evaluation of seedling characteristics}

The DH population and two parents were grown hydroponically in a greenhouse as shown in Fig. 1a. Figure 1b showed phenotypic difference in the seedling of the Huadama 6 and Huaai 11. Huadama 6 and Huaai 11 have significant differences in seedling characteristics. All traits values, except FOLW, in Huadamai 6 were higher than those in Huaai 11. The T-test showed that two parents were significantly different on all traits $(p<0.05)$ but FILW and FOLW (Table 1$).$

The 21 seedling characteristics in DH population were also significantly different, with a highly phenotypic variation. The variation coefficient ranged from $6.88 \%-$ $35.29 \%$. Heritability ranged from $89.86 \%$ to $97.05 \%$ (Table 1). Frequency distribution histogram of the 21 seedling characteristics were shown in Additional file 1: Figure S1. Shapiro-Wilk test showed that some of the characteristics fitted the normal distribution, including LAG (S2), SH (S1-S4), MRL (S1), SFW (S1), LL (except FILL), LW and LA. In addition, transgressive segregation was observed for all 21 seedling characteristics.

\section{Detection of QTLs}

A total of 70 QTLs on all barley chromosomes (except $4 \mathrm{H})$ were detected in 17 of the 21 seedling characteristics using ICIM mapping (Table 2; Fig. 2). No QTL was identified for SELL, FILW, THLW and FOLW. Of these, a single QTL contributed between $5.01 \%$ and $77.78 \%$ to the phenotypic variance, with LOD value ranging from 3.04 to 27.07 (Table 2; Additional file 2: Figure S2). Most QTLs primarily dispersed on chromosome $2 \mathrm{H}$ (35 QTLs), 3H (11 QTLs) and 7H (19 QTLs) (Figs. 2 and 3a). Ten colocalized chromosomal regions affected more than one 

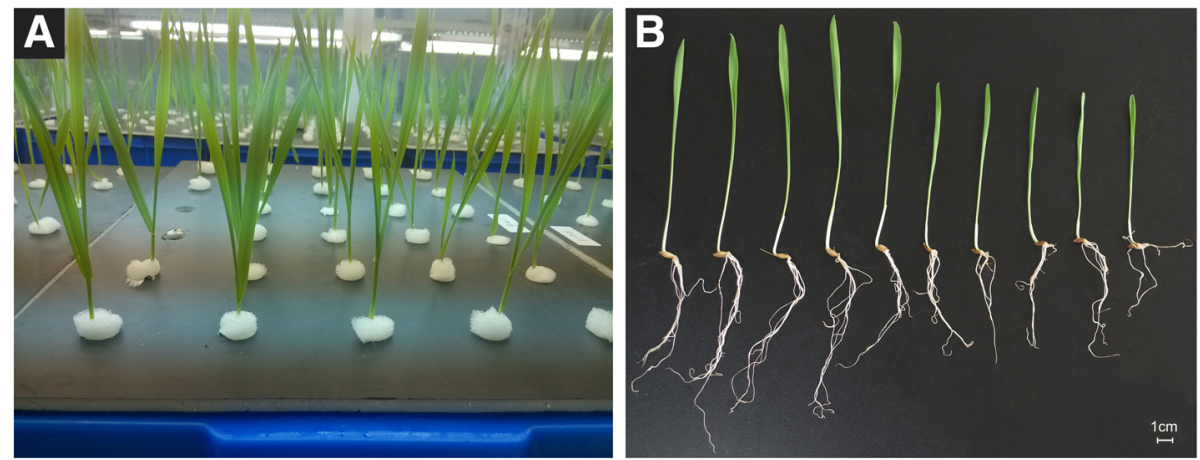

Fig. 1 Seedling production using the hydroponic culture and parents seedling phenotyping. a The parents and doubled haploid (DH) population were cultivated in plastic tanks with eight liters of Hoagland's nutrient solution. Throughout the experiments the roots were plunged into the nutrient solution. b Root systems and shoots of the parents Huadamai6 (from left 1-5) and Huaai11 (from left 6-10)

seedling characteristic distributed on chromosome $2 \mathrm{H}$, $3 \mathrm{H}$ and $7 \mathrm{H}$ (Table 3).

Dynamic QTL mapping on five seedling traits (LAG, SH, SFW, MRL and MRN) at four developmental stages identified 8 QTLs for LAG, 14 QTLs for SH, 8 QTLs for SFW, 8 QTLs for MRL and 4 QTLs for MRN (Table 2; Fig. 2). Phenotypic variation explained by single QTL ranged from $6.03 \%$ to $73.86 \%$ for LAG, from $5.49 \%$ to $24.90 \%$ for $\mathrm{SH}$, from $7.85 \%$ to $32.39 \%$ for SFW, from $8.08 \%$ to $16.23 \%$ for MRL and from $7.71 \%$ to $31.28 \%$ for MRN. Interestingly, we found that only one QTL for SH was detected at all four stages, 8 QTLs for LAG, SH, SFW and MRL were detected for two or three stages, but also some QTLs were specific for either S1, S2, S3 and S4 (Table 4; Fig. 4). In addition, we also observed that some QTLs, such as the QTL at $123 \mathrm{cM}$ on chromosome $2 \mathrm{H}$, not only expressed at all stages for $\mathrm{SH}$ but also affected the SFW at the S2 stage. Similar QTLs were identified at 127/129 $\mathrm{cM}$ and 137/139 cM on chromosome $2 \mathrm{H}$ and at $30 / 32 \mathrm{cM}$ and $80 / 81 \mathrm{cM}$ on chromosome $3 \mathrm{H}$. Two major QTLs for LAG ( $q L A G 2-$ 228 ) and SFW (qSFW2-202) explaining more than 20\% of the phenotypic variation at more than one stage of seedling growth was identified on chromosome $2 \mathrm{H}$. We analyzed the temporal-dynamics contribution of QTLs detected at any of the four stages to the proportion of explained phenotypic variation for five seedling characteristics (Fig. 5). The results showed that the proportion of explained phenotypic variance of some QTLs remained on a stable level at all stages of seedling growth; whereas, others substantially changed among the four stages of seedling growth.

We assessed four seedling characteristics (SLFW, RFW, SLDW and RDW) at S4 stage, and detected one QTL for SLFW, 2 QTLs for RFW, 3 QTLs for SLDW and 2 QTLs for RDW (Table 2; Fig. 2). A single QTL identified for these four seedling characteristics could individually explain $28.83 \%$ (SLFW), $9.81 \%-32.06 \%$
(RFW), 8.17\%-23.62\% (SLDW) and 10.58\%-20.22\% (RDW) of the phenotypic variation. These QTLs were almost invariably located on chromosome $2 \mathrm{H}$ except for QTL qSLDW7-45. The major QTL qSLFW2-202 was detected for SLFW on chromosome $2 \mathrm{H}$ around 127/ $129 \mathrm{cM}$ and co-located with QTLs for SFW at S1, S3 and S4 (qSFW2-202), MRN at S2 (qMRN2-199) and SLDW at S4 (qSLDW2-202). Another major QTL was identified on chromosome $2 \mathrm{H}$ around $137 / 139 \mathrm{cM}$ and had effect on MRN at S3 and S4 (qMRL2-214), RFW at S4 (qRFW2-209) and RDW at S4 (qRDW2-214).

For eight seedling characteristics (FILL, THLL, FOLL, SELW, FILA, SELA, THLA and FOLA), a total of 21 QTLs on chromosome 2H (nine QTLs), chromosome $3 \mathrm{H}$ (three QTLs), chromosome 6H (one QTL) and on $7 \mathrm{H}$ (eight QTLs) were identified. The LOD value ranged from 3.17 to 27.07 , and individual QTL accounted for $5.01 \%-77.78 \%$ of the phenotypic variation (Table 2; Additional file 2: Figure S2). Three, two, two, two, one, four, five, one and two QTLs were detected for FILL, THLL, FOLL, SELW, FILA, SELA, THLA and FOLA, respectively. Interestingly, we found that six major QTLs, qFILL7-154, qTHLL7-145, qFOLL7-237, qFILA7-134, qSELA7-142 and qTHLA7145, distributed on chromosome $7 \mathrm{H}$, had positive alleles from Huadamai 6. In addition, we also observed a number of QTLs that affected multiple traits, such as $127 / 129 \mathrm{cM}$ on chromosome $2 \mathrm{H}$.

\section{Discussion}

Seedling characteristics include stem-and-leaf and root systems. A good stem-and-leaf system in the seedling stage is the basis for seedlings growth potential of robust, strong plants that are resistant to stress. To sustain a strong seedling vigor and rapid seedling growth, seedling must produce abundant nutrition. The amount of nutrition production mainly depends on the first few leaves of the seedling [44]. In addition, growth and 
Table 1 The statistics of the 122 lines from DH population and parents for the 21 seedling characteristics

\begin{tabular}{|c|c|c|c|c|c|c|c|c|c|c|c|c|c|c|}
\hline \multirow[t]{2}{*}{ Traits $^{a}$} & \multirow[t]{2}{*}{ Stages $^{b}$} & \multicolumn{2}{|c|}{ Huadamai 6} & \multicolumn{2}{|c|}{ Huaai 11} & \multirow{2}{*}{$\begin{array}{l}\text { T } \\
\text { value }^{d}\end{array}$} & \multicolumn{7}{|c|}{ DH population } & \multirow[b]{2}{*}{$H^{f}$} \\
\hline & & Mean & $\mathrm{SD}^{c}$ & Mean & $\mathrm{SD}^{c}$ & & Max & Min & Mean & $\mathrm{SD}^{\mathrm{C}}$ & $\mathrm{CV}^{\mathrm{e}}$ & Skewness & Kurtosis & \\
\hline \multirow[t]{4}{*}{ LAG } & S1 & 1.90 & $<0.01$ & 1.67 & 0.27 & $2.15^{*}$ & 2.34 & 1.57 & 1.89 & 0.13 & 6.88 & 0.75 & 2.34 & 88.69 \\
\hline & S2 & 2.70 & $<0.01$ & 2.45 & 0.10 & $5.00^{*}$ & 3.50 & 2.10 & 2.80 & 0.26 & 9.29 & 0.01 & 0.13 & 93.92 \\
\hline & S3 & 3.90 & 0.33 & 3.42 & 0.23 & $2.71^{*}$ & 5.30 & 3.05 & 3.93 & 0.40 & 10.18 & 0.59 & 0.81 & 95.89 \\
\hline & S4 & 5.55 & 0.23 & 4.94 & 0.22 & $4.42^{* *}$ & 7.03 & 4.10 & 5.34 & 0.53 & 9.93 & 0.53 & 0.22 & 96.11 \\
\hline \multirow[t]{4}{*}{$\mathrm{SH}$} & S1 & 26.84 & 2.53 & 13.36 & 1.01 & $11.07^{* *}$ & 26.40 & 12.10 & 18.86 & 3.22 & 17.07 & 0.22 & -0.57 & 94.34 \\
\hline & S2 & 31.60 & 2.44 & 18.53 & 2.15 & $8.67^{* *}$ & 33.60 & 13.23 & 25.41 & 3.94 & 15.51 & -0.11 & -0.28 & 93.23 \\
\hline & S3 & 33.82 & 0.71 & 22.83 & 1.75 & $14.07^{* *}$ & 38.20 & 21.28 & 30.59 & 3.72 & 12.16 & -0.03 & -0.69 & 93.27 \\
\hline & S4 & 35.12 & 1.62 & 24.28 & 2.29 & $8.86^{* *}$ & 42.17 & 24.23 & 33.08 & 4.43 & 13.39 & -0.02 & -0.72 & 94.53 \\
\hline \multirow[t]{4}{*}{ MRL } & S1 & 14.03 & 1.43 & 7.45 & 0.76 & $8.32^{* *}$ & 14.76 & 5.47 & 10.05 & 2.04 & 20.30 & 0.25 & -0.33 & 89.97 \\
\hline & S2 & 14.03 & 1.08 & 9.22 & 0.77 & $8.64^{* *}$ & 19.68 & 7.50 & 11.67 & 2.39 & 20.48 & 0.90 & 0.87 & 91.39 \\
\hline & S3 & 14.80 & 0.63 & 11.18 & 1.42 & $5.59^{* *}$ & 23.13 & 8.03 & 14.77 & 3.57 & 24.17 & 0.47 & -0.56 & 89.95 \\
\hline & S4 & 15.53 & 0.43 & 11.40 & 1.29 & $6.69^{* *}$ & 23.70 & 9.43 & 15.15 & 3.42 & 22.57 & 0.51 & -0.47 & 89.86 \\
\hline \multirow[t]{4}{*}{ MRN } & S1 & 7.83 & 0.98 & 5.50 & 0.84 & $4.43^{* *}$ & 10.20 & 5.20 & 6.88 & 0.93 & 13.52 & 1.21 & 1.83 & 92.90 \\
\hline & S2 & 10.00 & 1.67 & 5.83 & 0.98 & $5.26^{* *}$ & 13.67 & 6.40 & 8.48 & 1.35 & 15.92 & 1.27 & 2.20 & 93.93 \\
\hline & S3 & 11.67 & 1.21 & 6.67 & 0.58 & $6.61^{* *}$ & 18.33 & 7.40 & 11.12 & 2.13 & 19.15 & 1.08 & 1.61 & 94.82 \\
\hline & S4 & 14.00 & 1.22 & 11.00 & 1.41 & $3.42^{*}$ & 27.33 & 9.50 & 16.76 & 3.47 & 20.70 & 0.83 & 0.61 & 92.23 \\
\hline \multirow[t]{4}{*}{ SFW } & S1 & 0.57 & 0.05 & 0.24 & 0.03 & $11.81^{* *}$ & 0.68 & 0.16 & 0.41 & 0.10 & 24.39 & 0.23 & -0.26 & 94.94 \\
\hline & S2 & 0.95 & 0.09 & 0.44 & 0.08 & $8.84^{* *}$ & 1.22 & 0.34 & 0.72 & 0.20 & 27.78 & 0.44 & -0.45 & 93.69 \\
\hline & S3 & 1.36 & 0.16 & 0.64 & 0.11 & $6.88^{* *}$ & 2.27 & 0.57 & 1.20 & 0.38 & 31.67 & 0.71 & 0.05 & 94.12 \\
\hline & S4 & 1.66 & 0.26 & 1.05 & 0.13 & $3.75^{* *}$ & 3.81 & 0.88 & 1.94 & 0.67 & 34.54 & 0.60 & -0.30 & 93.32 \\
\hline SLFW & S4 & 1.22 & 0.20 & 0.80 & 0.09 & $3.40^{*}$ & 2.87 & 0.64 & 1.44 & 0.50 & 34.72 & 0.69 & -0.11 & 93.79 \\
\hline RFW & S4 & 0.44 & 0.07 & 0.25 & 0.04 & $4.39^{* *}$ & 1.05 & 0.19 & 0.51 & 0.18 & 35.29 & 0.51 & -0.21 & 91.79 \\
\hline SLDW & S4 & 0.17 & 0.03 & 0.11 & 0.01 & $4.80^{* *}$ & 0.34 & 0.08 & 0.18 & 0.05 & 27.78 & 0.62 & -0.20 & 91.30 \\
\hline RDW & S4 & 0.04 & $<0.01$ & 0.02 & $<0.01$ & $5.91^{* *}$ & 0.08 & 0.02 & 0.04 & 0.01 & 25.00 & 0.45 & -0.34 & 91.28 \\
\hline FILL & & 13.87 & 0.66 & 8.93 & 0.64 & $13.17^{* *}$ & 14.50 & 6.80 & 10.85 & 1.73 & 15.94 & -0.25 & -0.65 & 97.05 \\
\hline SELL & & 25.94 & 1.65 & 14.28 & 0.76 & $12.97^{* *}$ & 25.10 & 11.20 & 18.11 & 3.18 & 17.56 & 0.04 & -0.51 & 93.07 \\
\hline THLL & & 26.63 & 2.00 & 17.44 & 1.94 & $7.70^{* *}$ & 28.68 & 14.57 & 22.32 & 2.97 & 13.31 & -0.06 & -0.21 & 91.93 \\
\hline FOLL & & 27.94 & 1.49 & 19.17 & 2.46 & $6.43^{* *}$ & 31.90 & 16.40 & 24.64 & 3.47 & 14.08 & -0.14 & -0.45 & 94.61 \\
\hline FILW & & 0.70 & $<0.01$ & 0.68 & 0.04 & 1.00 & 0.87 & 0.53 & 0.74 & 0.07 & 9.46 & -0.46 & 0.07 & 91.84 \\
\hline SELW & & 0.60 & $<0.01$ & 0.44 & 0.05 & $6.53^{* *}$ & 0.77 & 0.42 & 0.57 & 0.07 & 12.28 & 0.40 & 0.18 & 91.84 \\
\hline THLW & & 0.67 & 0.05 & 0.56 & 0.05 & $3.32^{* *}$ & 0.96 & 0.44 & 0.64 & 0.09 & 14.06 & 0.36 & 0.52 & 91.76 \\
\hline FOLW & & 0.68 & 0.04 & 0.73 & 0.06 & -1.53 & 1.08 & 0.50 & 0.76 & 0.12 & 15.79 & 0.29 & -0.32 & 94.07 \\
\hline FILA & & 8.06 & 0.38 & 5.06 & 0.29 & $15.32^{* *}$ & 9.37 & 3.86 & 6.63 & 1.26 & 19.00 & -0.04 & -0.64 & 95.64 \\
\hline SELA & & 12.92 & 0.82 & 5.35 & 0.92 & $13.06^{* *}$ & 14.26 & 4.65 & 8.66 & 2.07 & 23.90 & 0.38 & -0.44 & 92.68 \\
\hline THLA & & 14.74 & 1.54 & 8.16 & 1.55 & $7.03^{* *}$ & 21.61 & 6.05 & 11.97 & 2.84 & 23.73 & 0.44 & 0.43 & 91.93 \\
\hline FOLA & & 16.23 & 0.87 & 11.63 & 1.29 & $6.12^{* *}$ & 27.45 & 7.59 & 15.76 & 4.14 & 26.27 & 0.25 & -0.21 & 94.82 \\
\hline
\end{tabular}

arait abbreviations refer to Table 6

${ }^{\text {b }}$ S1 to S4 represented 13 th, 20th, 27th and 34th day after germination, respectively

${ }^{\mathrm{c}} \mathrm{S} D$ standard deviation

$d_{*}, * *$, significant at the probability level of 0.05 and 0.01

${ }^{\mathrm{e}} \mathrm{CV}$ coefficient of variation in \%

${ }^{\mathrm{f}} H$ heritability in \%

development of healthy plants mainly rely on the strong root system (long MRL, high RDW and enough MRN), which were closely related to final grain yield and quality
[45]. Some studies indicated that MRL and MRN were one of the most desirable traits contributing to drought avoidance, and RDW was another important parameter 
Table 2 QTLs detected for 21 seedling characteristics under hydroponic culture conditions in the DH populations identified using inclusive composite interval mapping

\begin{tabular}{|c|c|c|c|c|c|c|c|c|c|}
\hline Traits $^{a}$ & Stages $^{b}$ & QTLS & $\mathrm{Chr}^{\mathrm{C}}$ & Pos. $^{d}$ & Left Marker $^{\mathrm{e}}$ & Right Marker ${ }^{\mathrm{e}}$ & LOD & $\mathrm{PVE}^{f}$ & $\mathrm{Add}^{\mathrm{g}}$ \\
\hline \multirow[t]{8}{*}{ LAG } & S1 & qLAG7-101 & 7 & 74 & 7_489795725 & 7HL_25508816 & 23.14 & 73.86 & -0.11 \\
\hline & S1 & qLAG7-187 & 7 & 116 & 5_496886371 & M_254133_378 & 13.13 & 31.58 & 0.07 \\
\hline & S1 & qLAG7-370 & 7 & 209 & 7_31360519 & 7_28180957 & 3.08 & 6.03 & -0.03 \\
\hline & S2 & $q L A G 2-228$ & 2 & 162 & 2HL_18227895 & 2_579576154 & 10.31 & 26.1 & 0.13 \\
\hline & S2 & $q L A G 7-80$ & 7 & 66 & 7HL_37199773 & 7HL_4313756 & 5.26 & 12.51 & -0.09 \\
\hline & S3 & $q L A G 2-228$ & 2 & 162 & 2HL_18227895 & 2_579576154 & 8.81 & 26.84 & 0.21 \\
\hline & S4 & qLAG2-206 & 2 & 132 & 2_531230596 & 2HL_43143355 & 9.39 & 27.70 & 0.30 \\
\hline & S4 & qLAG5-219 & 5 & 193 & M_148497_192 & 5_428226858 & 3.17 & 8.39 & 0.15 \\
\hline \multirow[t]{14}{*}{ SH } & S1 & qSH1-56 & 1 & 40 & $1 \mathrm{H} \_10744858$ & 1_258171231 & 4.53 & 7.50 & -0.88 \\
\hline & S1 & qSH2-191 & 2 & 123 & 2_514353957 & 2HL_13648618 & 10.14 & 18.61 & 1.53 \\
\hline & S1 & qSH3-51 & 3 & 32 & 3HL_15958290 & 3HL_32354397 & 7.03 & 13.49 & 1.31 \\
\hline & S1 & qSH3-369 & 3 & 212 & 3_26035945 & 3_28844640 & 3.41 & 5.49 & 0.75 \\
\hline & S1 & qSH5-18 & 5 & 42 & Ebmatc40 & M_86861_975 & 12.54 & 24.40 & 1.67 \\
\hline & S1 & qSH5-153 & 5 & 141 & 5HL_43331862 & M_1634918_588 & 6.13 & 11.25 & -1.12 \\
\hline & S1 & qSH7-219 & 7 & 127 & 7HS_26227899 & 7_348795436 & 5.51 & 9.17 & 0.98 \\
\hline & S2 & qSH2-191 & 2 & 123 & 2_514353957 & 2HL_13648618 & 10.54 & 17.74 & 1.83 \\
\hline & S2 & qSH3-44 & 3 & 30 & 3HL_29995337 & 3_510997641 & 7.33 & 11.77 & 1.47 \\
\hline & S3 & qSH2-191 & 2 & 123 & 2_514353957 & 2HL_13648618 & 9.07 & 19.06 & 1.79 \\
\hline & S3 & qSH3-51 & 3 & 32 & 3HL_15958290 & 3HL_32354397 & 5.54 & 10.92 & 1.37 \\
\hline & S3 & qSH7-199 & 7 & 121 & 7HL_22161891 & 7HS_6744377 & 8.30 & 17.43 & 1.56 \\
\hline & S4 & qSH2-191 & 2 & 123 & 2_514353957 & 2HL_13648618 & 9.55 & 22.05 & 2.29 \\
\hline & S4 & qSH7-184 & 7 & 113 & M_171247_237 & 7HL_36983527 & 10.40 & 24.90 & 2.22 \\
\hline \multirow[t]{8}{*}{ MRL } & S1 & $9 M R L 7-27$ & 7 & 25 & 7HL_2460896 & 7HL_27281835 & 3.69 & 13.16 & 0.75 \\
\hline & S2 & $9 M R L 7-27$ & 7 & 25 & 7HL_2460896 & 7HL_27281835 & 4.04 & 12.92 & 0.88 \\
\hline & S3 & qMRL2-113 & 2 & 70 & 2HL_18957514 & 2HL_20952058 & 4.09 & 10.58 & -1.21 \\
\hline & S3 & qMRL2-214 & 2 & 139 & 2HL_766321 & 2_544135082 & 6.06 & 16.23 & 1.54 \\
\hline & S3 & qMRL3-117 & 3 & 80 & 3HL_39880616 & 3_440999767 & 4.58 & 12.65 & -1.27 \\
\hline & S4 & qMRL2-113 & 2 & 70 & 2HL_18957514 & 2HL_20952058 & 3.27 & 8.08 & -1.01 \\
\hline & S4 & qMRL2-214 & 2 & 139 & 2HL_766321 & 2_544135082 & 5.42 & 13.86 & 1.36 \\
\hline & S4 & qMRL3-117 & 3 & 80 & 3HL_39880616 & 3_440999767 & 3.28 & 8.78 & -1.02 \\
\hline \multirow[t]{4}{*}{ MRN } & S1 & aMRN2-188 & 2 & 119 & 2_456666117 & 2_497016140 & 11.67 & 31.28 & 0.58 \\
\hline & S2 & qMRN3-15 & 3 & 10 & 3HL_8468228 & HvM70 & 3.34 & 7.71 & 0.26 \\
\hline & S2 & qMRN2-199 & 2 & 127 & 2HL_22930005 & 2HL_17075593 & 6.25 & 19.08 & 0.66 \\
\hline & S3 & aMRN3-120 & 3 & 81 & 3HL_37773053 & 3_426808044 & 3.22 & 11.53 & 0.73 \\
\hline \multirow[t]{8}{*}{ SFW } & S1 & qSFW2-202 & 2 & 129 & 2HL_34260490 & 2_524782265 & 10.55 & 25.71 & 0.05 \\
\hline & S1 & qSFW7-157 & 7 & 98 & 7HL_39790706 & 7_431414178 & 6.03 & 13.50 & 0.04 \\
\hline & S2 & qSFW2-48 & 2 & 33 & M_1606997_622 & 2HS_1353446 & 3.22 & 7.85 & -0.06 \\
\hline & S2 & qSFW2-191 & 2 & 123 & 2_514353957 & 2HL_13648618 & 11.70 & 32.39 & 0.12 \\
\hline & S3 & qSFW2-90 & 2 & 59 & 2HS_30524211 & 2HS_17957603 & 3.04 & 9.30 & -0.12 \\
\hline & S3 & qSFW2-202 & 2 & 129 & 2HL_34260490 & 2_524782265 & 8.06 & 27.06 & 0.22 \\
\hline & \$4 & qSFW2-90 & 2 & 59 & 2HS_30524211 & 2HS_17957603 & 3.64 & 10.78 & -0.22 \\
\hline & S4 & qSFW2-202 & 2 & 129 & 2HL_34260490 & 2_524782265 & 9.26 & 30.50 & 0.40 \\
\hline SLFW & S4 & qSLFW2-202 & 2 & 129 & 2HL_34260490 & 2_524782265 & 8.62 & 28.83 & 0.29 \\
\hline
\end{tabular}


Table 2 QTLs detected for 21 seedling characteristics under hydroponic culture conditions in the DH populations identified using inclusive composite interval mapping (Continued)

\begin{tabular}{|c|c|c|c|c|c|c|c|c|c|}
\hline Traits $^{a}$ & Stages $^{b}$ & QTLS & $\mathrm{Chr}^{\mathrm{C}}$ & Pos. $^{d}$ & Left Marker $^{\mathrm{e}}$ & Right Marker ${ }^{\mathrm{e}}$ & LOD & $\mathrm{PVE}^{f}$ & $\mathrm{Add}^{9}$ \\
\hline \multirow[t]{2}{*}{ RFW } & S4 & qRFW2-90 & 2 & 59 & 2HS_30524211 & 2HS_17957603 & 3.60 & 9.81 & -0.06 \\
\hline & S4 & qRFW2-209 & 2 & 137 & M_165611_94 & 2_535589467 & 10.15 & 32.06 & 0.11 \\
\hline \multirow[t]{3}{*}{ SLDW } & S4 & $q S L D W 2-120$ & 2 & 73 & 2HL_44835824 & 2HL_10858514 & 4.92 & 13.22 & -0.02 \\
\hline & \$4 & qSLDW2-202 & 2 & 129 & 2HL_34260490 & 2_524782265 & 8.37 & 23.62 & 0.03 \\
\hline & S4 & qSLDW7-45 & 7 & 41 & 7HL_34924967 & M_205503_1634 & 3.16 & 8.17 & -0.02 \\
\hline \multirow[t]{2}{*}{ RDW } & S4 & qRDW2-130 & 2 & 78 & 2HL_18855931 & M_223185_603 & 3.20 & 10.58 & -0.01 \\
\hline & S4 & aRDW2-214 & 2 & 139 & 2HL_766321 & 2_544135082 & 6.13 & 20.22 & 0.01 \\
\hline \multirow[t]{3}{*}{ FILL } & & qFILL2-243 & 2 & 184 & 2HL_19715945 & 2_598509820 & 3.75 & 5.28 & -0.40 \\
\hline & & qFILL3-31 & 3 & 23 & 3HL_38531260 & 3HL_41243504 & 3.43 & 5.01 & 0.41 \\
\hline & & qFILL7-154 & 7 & 97 & 7_440111505 & 7HL_39790713 & 22.87 & 48.43 & 1.21 \\
\hline \multirow[t]{2}{*}{ THLL } & & qTHLL6-130 & 6 & 105 & 6HL_13081351 & $6 \mathrm{HL} \_35014660$ & 5.05 & 7.62 & 0.82 \\
\hline & & qTHLL7-145 & 7 & 94 & Bmag746 & 7_318484923 & 16.28 & 30.43 & 1.64 \\
\hline \multirow[t]{2}{*}{ FOLL } & & qFOLL2-190 & 2 & 122 & 2_496663791 & 2_514353957 & 4.91 & 13.34 & 1.36 \\
\hline & & qFOLL7-237 & 7 & 136 & 7_382544975 & 7HS_29196961 & 7.00 & 22.36 & 1.64 \\
\hline SELW & & qSELW2-202 & 2 & 129 & 2HL_34260490 & 2_524782265 & 4.83 & 16.65 & 0.03 \\
\hline \multirow[t]{4}{*}{ FILA } & & qFILA2-202 & 2 & 129 & 2HL_34260490 & 2_524782265 & 6.55 & 12.05 & 0.47 \\
\hline & & qFILA2-238 & 2 & 176 & 2_588885691 & 2HL_14160939 & 5.48 & 9.94 & -0.41 \\
\hline & & qFILA3-26 & 3 & 19 & 3HL_42780152 & 3_534961137 & 3.17 & 5.56 & 0.31 \\
\hline & & qFILA7-134 & 7 & 88 & 7HL_37824340 & 7_460649517 & 14.82 & 32.17 & 0.71 \\
\hline \multirow[t]{5}{*}{ SELA } & & qSELA2-199 & 2 & 127 & 2HL_22930005 & 2HL_17075593 & 8.34 & 16.19 & 0.93 \\
\hline & & qSELA2-243 & 2 & 184 & 2HL_19715945 & 2_598509820 & 4.10 & 7.41 & -0.57 \\
\hline & & qSELA3-51 & 3 & 32 & 3HL_15958290 & $3 \mathrm{HL} \_32354397$ & 3.20 & 5.98 & 0.56 \\
\hline & & qSELA7-142 & 7 & 93 & 7HL_39750192 & 7HL_10412411 & 27.07 & 77.78 & 1.83 \\
\hline & & qSELA7-175 & 7 & 108 & 1H_82374297 & 7HS_31863896 & 9.82 & 19.98 & -0.93 \\
\hline THLA & & qTHLA7-145 & 7 & 94 & Bmag746 & 7_318484923 & 7.08 & 23.33 & 1.37 \\
\hline \multirow[t]{2}{*}{ FOLA } & & qFOLA2-202 & 2 & 129 & 2HL_34260490 & 2_524782265 & 4.13 & 12.23 & 1.55 \\
\hline & & qFOLA7-184 & 7 & 113 & M_171247_237 & 7HL_36983527 & 5.27 & 16.75 & 1.71 \\
\hline
\end{tabular}

${ }^{\text {a Trait abbreviations refer to Table } 6}$

${ }^{\mathrm{b}} \mathrm{S} 1$ to $\mathrm{S} 4$ represented 13 th, 20th, 27th and 34th day after germination, respectively

${ }^{\mathrm{C}}$ Chromosome

${ }^{\mathrm{d}}$ Genetic distance (in centimorgan) of each QTL from the top of the corresponding chromosome

${ }^{\mathrm{e}}$ Markers in bold indicate the nearest ones linked to putative QTLs

${ }^{f}$ The phenotypic variation explained (in \%) by each QTL

${ }^{g}$ Additive effect, positive values indicate that the alleles from Huadamai 6 increased trait values

for the roots associated with water use efficiency and long-term drought $[46,47]$. Recent studies have also confirmed that most of the seedling traits, such as leaf area (LA), seedling height (SH), seedling fresh weight (FW), seedling dry weight (DW), shoot dry weight (SDW) and root dry weight (RDW), were closely and positively correlated with yield component traits [48]. Previous genetic research on barley were focused mainly on the later stage; thus, the genetic mechanism underlying seedling characteristics is still lacking. In this study, we assessed QTLs underlying 21 seedling characteristics (including five seedling characteristics assessed at four stages of seedling growth) under hydroponic culture conditions and compared the QTL expression pattern among four different seedling growth stages.

\section{Advantages of hydroponic culture}

For larger populations, it is difficult to assess seedling characteristics, especially whole-root systems, and for multi-stage barley planted in soil. Hydroponics culture allowed us to assess the same seedling over multi-stages. Genes or QTLs expression under hydroponic conditions might be different from field trials. However, the expression of genes or QTLs is always affected by the environment, while complex environments and uneven fertilizing in the field trial will affect the genetic mechanism of 


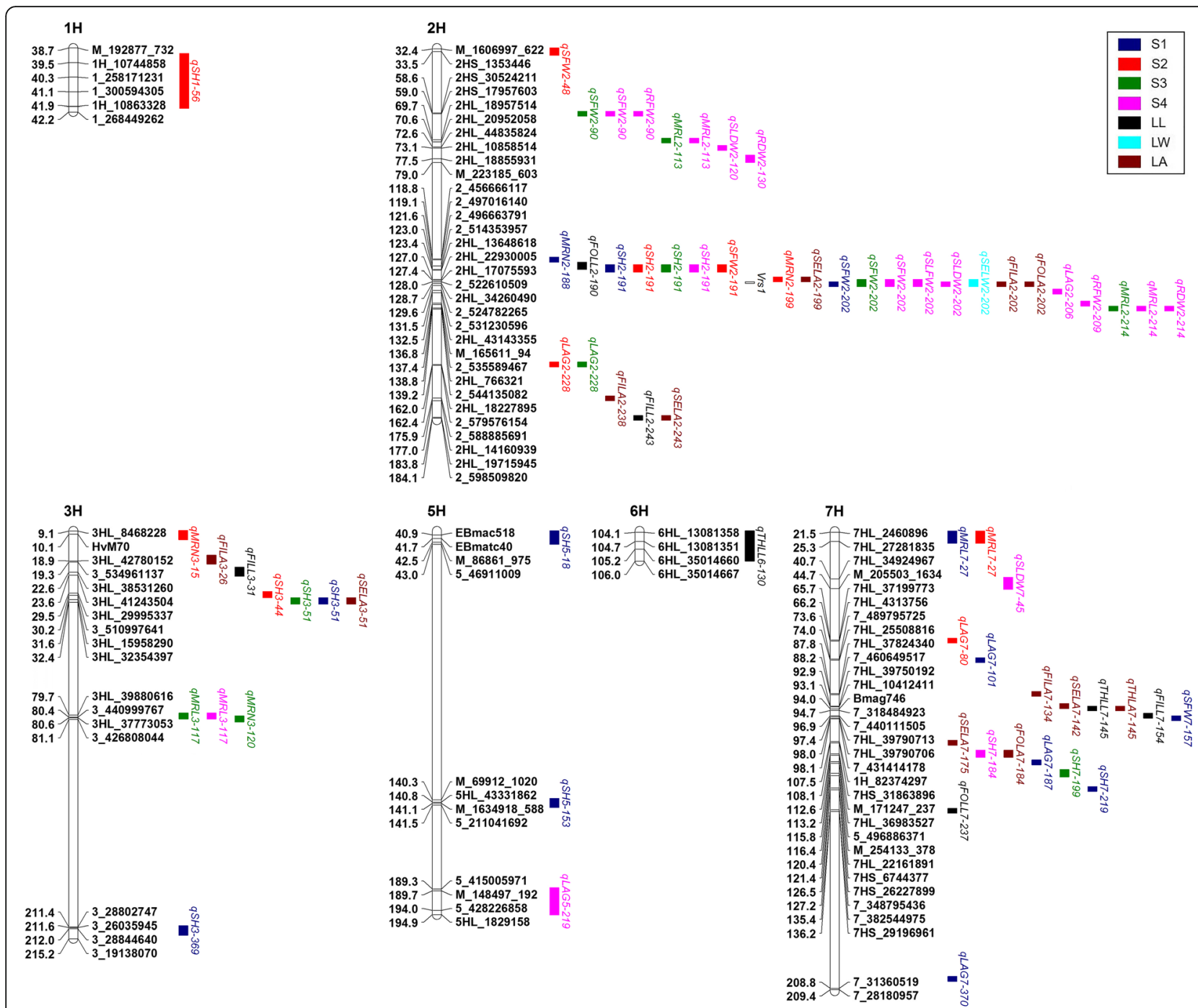

Fig. 2 Chromosome locations of QTLs associated with 17 seedling characteristics detected in the Huaai $11 \times$ Huadamai 6 DH population. QTL bars represented the 1.5-LOD support intervals from ICIM mapping. Genetic distance in centimorgans (CM) was placed at left. The row type trait was shown on linkage map (unfilled bars). Trait abbreviations refer to Table 6. S1 to S4 represented the 13th, 20th, 27th and 34th day after germination, respectively

seedling characteristics, and may not reflect the intrinsic genetic program of barley seedling characteristics [19]. Thus, stable and consistent environmental control is needed to assess seedling characteristics. Recent studies have shown that QTLs identified under hydroponics conditions corresponded to QTLs detected in field trials, and suggested that a hydroponic system is a fast and cost-effective method for early QTL detection and marker-assisted allelic selection [30]. Consequently, we established a hydroponic system with homogeneous-growth conditions to evaluate barley-seedling characteristics. Temperature, humidity and lighting conditions were controlled by the automatic control system, and the nutrient solution was renewed every seventh day to ensure adequate nutrition. QTLs identified in this environment could reflect the intrinsic genetic mechanisms underlying barley seedling characteristics.

\section{QTL for seedling characteristics}

With the same DH population used in this study, Ren et al. [49-52], Liu et al. [33] and Wang et al. [34] identified certain QTLs for physiological and morphological traits of flag leaf and some agronomic and quality traits (Additional file 3: Figure S3). Similar to their study, most of the QTLs identified in this study were also located on chromosome $2 \mathrm{H}$ and $7 \mathrm{H}$. We found that some QTLs for seedling characteristics were co-located with QTLs for yield or yield-related traits identified in previous studies. For example, a significant QTL qSH2-191 for SH detected in all stages of seedling growth was close to the SNP marker 2_514353957, which is likely the same to the yield- 


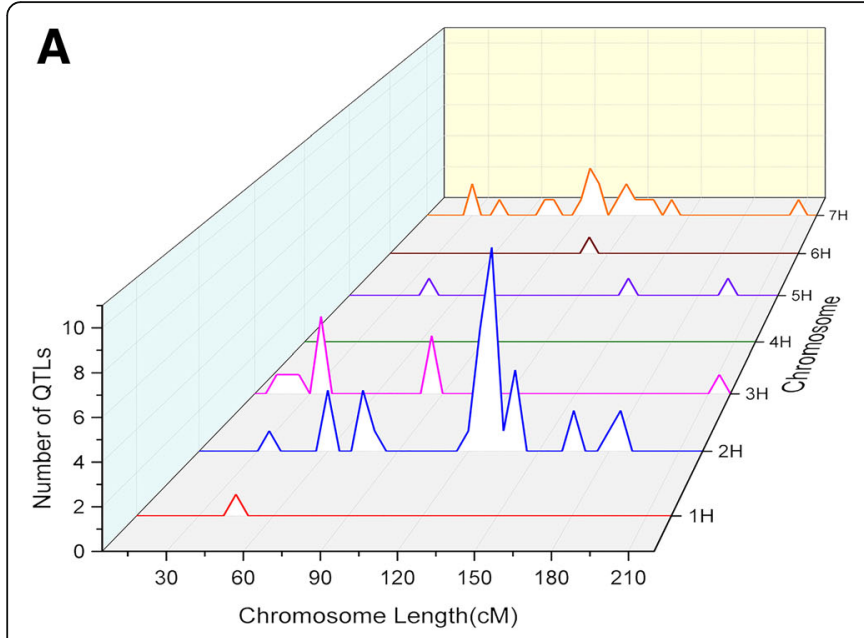

B

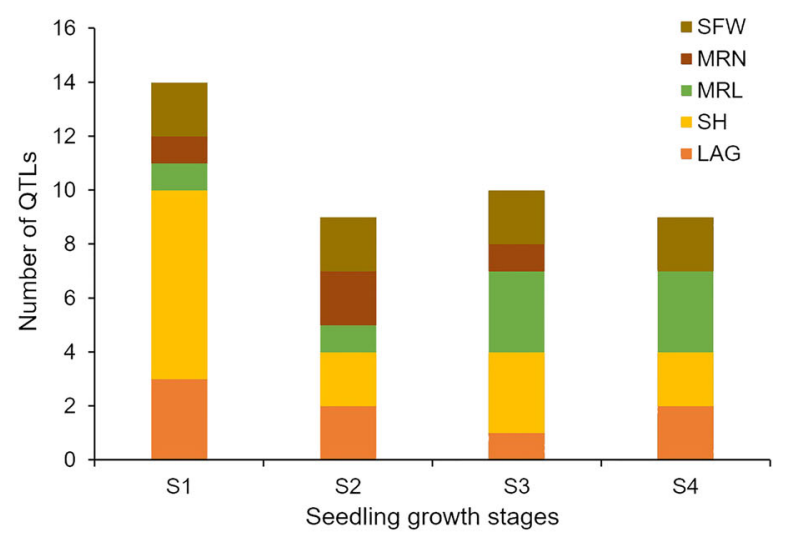

C ${ }_{2 \mathrm{H}}$
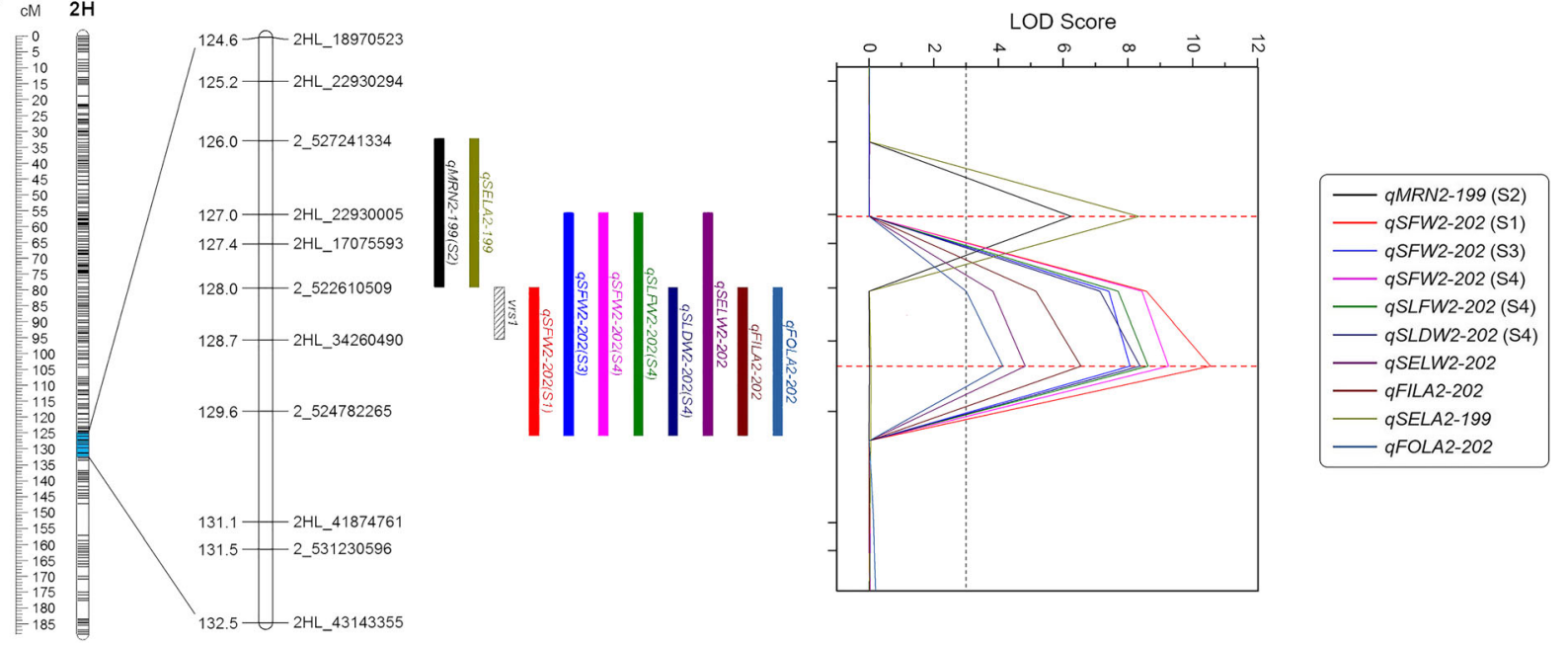

Fig. 3 a Distribution characteristics of QTLs for 17 seedling characteristics in barley genome. $\mathbf{b}$ The number of QTLs for five seedling characteristics at each stage of seedling growth. Trait abbreviations refer to Table 1. c QTL-likelihood curves of LOD scores showed the locations of QTL for some seedling characteristics on chromosome $2 \mathrm{H}$ in the vicinity of Vrs 7 locus. Length of the rectangles corresponded to the 1.5-LOD support intervals based on the results of ICIM. Vrs 1 locus was indicated by hatched bars. The black dash line indicated that the LOD value was 3.0

related QTL $q$ Sms2-7 and $q$ Tgw2-1 reported by Wang et al. [34] (Table 2; Additional file 3: Figure S3). In addition, the co-localized QTLs for THLL, SELA and THLA were detected on chromosome $7 \mathrm{H}$ and are likely the same to qRWC7-9 and qSPD7-9 for physiological and morphological traits of flag leaf at the pre-filling stage reported by Liu et al. [33] (Table 2; Additional file 3: Figure S3). These results suggested that seedling characteristics and yield are related to a certain extent.

In previous studies, QTLs conferring seedling height (SH) $[29,30]$, root dry weight (RDW) $[46,53-55]$ and stem-and-leaf dry weight (SLDW) [30, 42, 46, 53, 55] were reported on seven linkage groups, while QTLs for seedling fresh weight (SFW), leaf age (LAG) and main root number (MRN) were rarely reported in barley. QTLs for root length were identified on chromosome $1 \mathrm{H}, 2 \mathrm{H}, 3 \mathrm{H}, 4 \mathrm{H}, 5 \mathrm{H}$ and $7 \mathrm{H}[46,53-55]$, and QTLs conferring root fresh weight (RFW) were previously reported on chromosome $1 \mathrm{H}, 2 \mathrm{H}$ and $5 \mathrm{H}[29,42]$. Recently, Hoffmann et al. [30] analyzed QTL underlying number of leaves longer than $2 \mathrm{~cm}$ after 14 days and length of the youngest completely unfolded leaf after 14 days, and found six QTLs for leaf number on chromosome $2 \mathrm{H}, 4 \mathrm{H}, 6 \mathrm{H}$ and $7 \mathrm{H}$, and nine QTLs for leaf length on all seven chromosomes in wild barley introgression lines (S42ILs). By using GrainGenes3.0 website (http://wheat.pw.usda.gov/GG3/) to compare the genetic markers with those results present in this study, we found that some QTLs identified in our study are likely same to the QTLs reported in the past research. Such as, $q \mathrm{SH} 3-44$ for $\mathrm{SH}$ is likely the same to the QTL QHei.S42IL-3H reported by Hoffmann et al. [30]. Arifuzzaman et al. [46] reported that QTL QSdw.S42.2H.c for SLDW on chromosome $2 \mathrm{H}$ was 
Table 3 Putative pleiotropy or linkage of QTLs on linkage groups in barley

\begin{tabular}{|c|c|c|c|c|c|c|c|}
\hline $\mathrm{Chr}^{a}$ & Pos. $^{b}$ & Left Marker $^{c}$ & Right Marker ${ }^{c}$ & Involved traits $^{d}$ & LOD & $\mathrm{PVE}^{\mathrm{e}}$ & Add $^{\dagger}$ \\
\hline $2 \mathrm{H}$ & 59 & 2HS_30524211 & 2HS_17957603 & SFW, RFW & $3.04-3.60$ & $9.30-10.78$ & - \\
\hline $2 \mathrm{H}$ & $122 / 123$ & 2_496663791 & $2 \mathrm{HL} \_13648618$ & FOLL, SH, SFW & $4.91-11.70$ & $13.34-32.39$ & + \\
\hline $2 \mathrm{H}$ & $127 / 129$ & 2HL_22930005 & 2_524782265 & $\begin{array}{l}\text { MRN, SELA, SFW, } \\
\text { SLFW, SLDW, SELW, } \\
\text { FILA, FOLA }\end{array}$ & $4.07-10.55$ & $12.05-30.50$ & + \\
\hline $2 \mathrm{H}$ & $137 / 139$ & M_165611_94 & 2_544135082 & RFW, MRL, RDW & $5.42-10.15$ & $13.86-32.06$ & + \\
\hline $2 \mathrm{H}$ & 184 & 2HL_19715945 & 2_598509820 & FILL, SELA & $3.75-4.10$ & $5.28-7.41$ & - \\
\hline $3 \mathrm{H}$ & $30 / 32$ & 3HL_29995337 & 3HL_32354397 & SH, SELA & $3.20-7.33$ & 5.98-13.49 & + \\
\hline $3 \mathrm{H}$ & $80 / 81$ & 3HL_39880616 & 3_426808044 & MRL, MRN & $3.22-4.58$ & $8.78-12.65$ & $+/-$ \\
\hline 7H & $93 / 94$ & 7HL_39750192 & 7_318484923 & SELA, THLL, THLA & $7.08-27.07$ & 23.33-77.78 & + \\
\hline 7H & $97 / 98$ & 7_440111505 & 7_431414178 & FILL, SFW & $6.03-22.87$ & $13.50-48.43$ & + \\
\hline 7H & 113 & M_171247_237 & 7HL_36983527 & SH, FOLA & $5.27-10.40$ & $16.75-24.90$ & + \\
\hline
\end{tabular}

${ }^{\mathrm{a}}$ Chromosome

${ }^{\mathrm{b}}$ Genetic distance (in centimorgan) of each QTL from the top of the corresponding chromosome

${ }^{\mathrm{C}}$ Markers in bold indicated the nearest ones linked to putative QTLs

${ }^{\mathrm{d}}$ Trait abbreviations refer to Table 6

'The phenotypic variation explained (in \%) by each QTL

${ }^{f}$ Additive effect; +, positive allele coming from Huadamai 6 ; - , positive allele coming from Huaai 11

linked with the marker bPb-8143, and since the $\mathrm{bPb}$ 8143 is near the morphological marker Vrs1, as inferred from GrainGenes3.0 (http://wheat.pw.usda.gov/ GG3/), we suggested that a co-localized QTLs for SLDW, SFW, SLFW, MRN, FILA, SELW, SELA and FOLA identified in our study is likely the same to the QTL QSdw.S42.2H.c. This QTL may be an important locus for controlling stem-and-leaf related traits in barley. The SNP marker 2HL_34260490 may be useful for marker-assisted selection (MAS) in barley breeding.

In addition, some new QTLs were also detected in this study. QTL for SH (qSH7-184) on chromosome 7H and
QTL for RFW ( $q R F W 2-90$ and $q R F W 2-209$ ) on chromosome $2 \mathrm{H}$, are likely different from the QTL reported by $\mathrm{Xu}$ et al. [29]. The QTL for MRL ( $q M R L 2-$ 113 and $q M R L 3-117)$, QTL for RDW ( $q R D W 2-130$ and $q R D W 2-214)$ and QTL for MRN (qMRN3-120) are likely different from those QTLs reported previously [42, 46]. The QTL, qMRL7-27 (S1 and S2), located on chromosome $7 \mathrm{H}$, is different from the QRI.S42IL7H.a and QRl.S42IL-7H.b, as reported by Hoffmann et al. [30]. The $q M R L 2-214$ (S3 and S4) for MRL, mapped together with $q R D W 2-214$ (S4) for RDW and $q R F W 2-209$ (S4) for RFW on chromosome $2 \mathrm{H}$, are different from those QTLs on chromosome $2 \mathrm{H}$,

Table 4 QTLs detected at two or more different stages of seedling growth

\begin{tabular}{|c|c|c|c|c|c|c|c|c|c|c|c|c|c|c|c|c|c|}
\hline \multirow[t]{2}{*}{ Traits $^{a}$} & \multirow[t]{2}{*}{ Chr. $^{\text {b }}$} & \multirow[t]{2}{*}{ Pos. $^{c}$} & \multirow[t]{2}{*}{ Left Marker $^{d}$} & \multirow[t]{2}{*}{ Right Marker ${ }^{d}$} & \multicolumn{4}{|l|}{ LOD } & \multicolumn{5}{|l|}{$\mathrm{PVE}^{f}$} & \multicolumn{4}{|c|}{$\mathrm{Add}^{g}$} \\
\hline & & & & & $\mathrm{S} 1^{\mathrm{e}}$ & S2 & S3 & S4 & S1 & S2 & S3 & S4 & Mean & S1 & S2 & S3 & S4 \\
\hline \multirow[t]{2}{*}{$\mathrm{SH}$} & $2 \mathrm{H}$ & 123 & 2_514353957 & 2HL_13648618 & 10.14 & 10.54 & 9.07 & 9.55 & 18.61 & 17.74 & 19.06 & 22.05 & 19.37 & 1.53 & 1.83 & 1.79 & 2.29 \\
\hline & $3 \mathrm{H}$ & $30 / 32$ & 3HL_29995337 & 3HL_32354397 & 7.03 & 7.33 & 5.54 & & 13.49 & 11.77 & 10.92 & & 12.06 & 1.31 & 1.47 & 1.37 & \\
\hline \multirow[t]{2}{*}{ SFW } & $2 \mathrm{H}$ & 59 & 2HS_30524211 & 2HS_17957603 & & & 3.04 & 3.64 & & & 9.30 & 10.78 & 10.04 & & & -0.12 & -0.22 \\
\hline & $2 \mathrm{H}$ & 129 & 2HL_34260490 & 2_524782265 & 10.55 & & 8.06 & 9.26 & 25.71 & & 27.06 & 30.50 & 27.76 & 0.05 & & 0.22 & 0.40 \\
\hline LAG & $2 \mathrm{H}$ & 162 & 2HL_18227895 & 2_579576154 & & 10.31 & 8.81 & & & 26.10 & 26.84 & & 26.47 & & 0.13 & 0.21 & \\
\hline \multirow[t]{4}{*}{ MRL } & $2 \mathrm{H}$ & 70 & 2HL_18957514 & 2HL_20952058 & & & 4.09 & 3.27 & & & 10.58 & 8.08 & 9.33 & & & -1.21 & -1.01 \\
\hline & $2 \mathrm{H}$ & 139 & 2HL_766321 & 2_544135082 & & & 6.06 & 5.42 & & & 16.23 & 13.86 & 15.05 & & & 1.54 & 1.36 \\
\hline & $3 \mathrm{H}$ & 80 & 3HL_39880616 & 3_440999767 & & & 4.58 & 3.28 & & & 12.65 & 8.78 & 10.72 & & & -1.27 & -1.02 \\
\hline & $7 \mathrm{H}$ & 25 & 7HL_2460896 & 7HL_27281835 & 3.69 & 4.04 & & & 13.16 & 12.92 & & & 13.04 & 0.75 & 0.88 & & \\
\hline
\end{tabular}

${ }^{\text {a }}$ Trait abbreviations refer to Table 6

${ }^{\mathrm{b}}$ Chromosome

'Genetic distance (in centimorgan) of each QTL from the top of the corresponding chromosome

${ }^{\mathrm{d}}$ Markers in bold indicated the nearest ones linked to putative QTLS

e $\$ 1$ to S4 represented 13th, 20th, 27th and 34th day after germination, respectively

${ }^{\mathrm{f}}$ The phenotypic variation explained (in \%) by each QTL

${ }^{g}$ Additive effect, positive values indicated that the alleles from Huadamai 6 increased trait values 


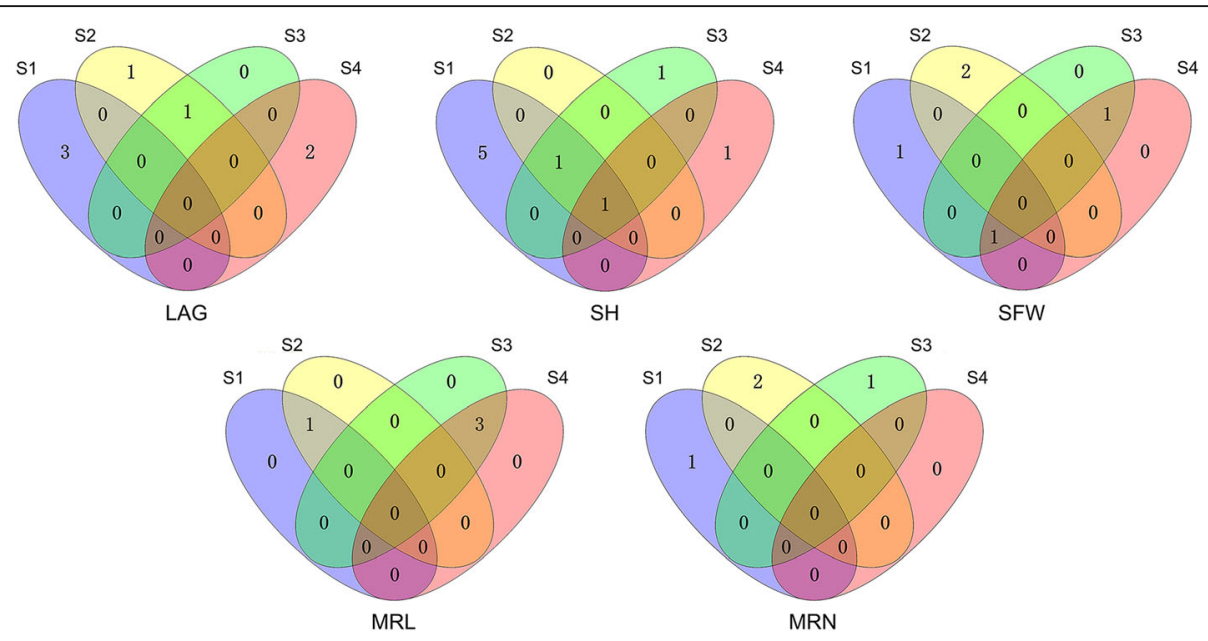

Fig. 4 Venn diagram of QTLS detected for five seedling characteristics under hydroponic culture conditions at four developmental stages of seedling growth. Trait abbreviations refer to Table 6. S1 to S4 represented the 13th, 20th, 27th and 34th day after germination, respectively

as reported previously $[55,56]$. This region may be important for controlling seedling root traits in barley.

\section{Selective expression of QTLs}

According to developmental genetics, different QTLs may have different expression dynamics during trait development [7, 57]. Previous studies focused mainly on late-growth stages, where analysis was limited to the performance of a trait at a fixed time or stage of ontogenesis [33, 34, 58]. In the present study, we assessed five seedling characteristics (LAG, SH, SFW, MRL and MRN) at four stages of seedling growth (13th, 20th, 27th and 34th day-after germination) to reveal the QTL expression pattern.

A total of 42 QTLs involved 29 regions were detected for these five traits at four stages of seedling growth

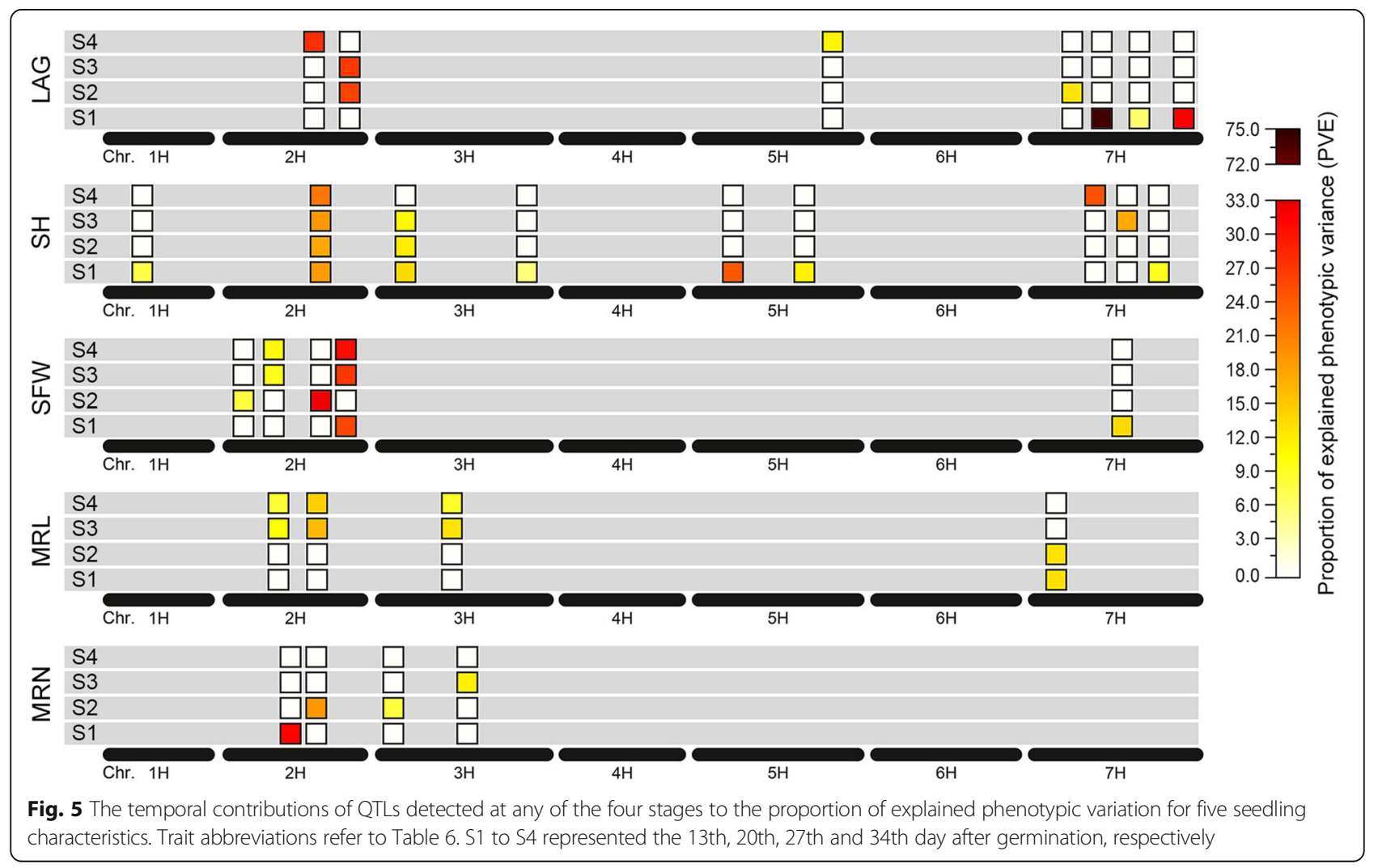


(Table 2; Fig. 4). Although the number of QTL expressed in each stage was approximately the same, only 9 regions were continually expressed in two or more different stages of seedling growth (Table 4; Figs. 3b and 4). Of these, only one of the nine regions was persistently expressed at all stages (Table 4; Figs. 4 and 5). The majority of the 29 regions for these five seedling characteristics were selectively expressed at different developmental stages. This result is in agreement with other studies where different QTLs could be identified at different growth stages, where only a few co-localized QTLs were detected at all stages $[7,59,60]$. The regions that continually expressed at different growth stages might play an important role in the growth and development of these characteristics. However, these regions do not always produce the same effect at each stage but show different developmental influences in different seedling growth stages. For example, two co-localized regions for $\mathrm{SH}$ were identified on chromosome $2 \mathrm{H}$ and $3 \mathrm{H}$; its contribution to the phenotypic variance undergoes temporal changes. On chromosome $2 \mathrm{H}$, a colocalized region contribution to the phenotypic variance decreased from $18.61 \%$ at S1 to $17.74 \%$ at S2 and then gradually increased until S4 (22.05\%). Differently, a colocalization region on chromosome $3 \mathrm{H}$ contribution to the phenotypic variance gradually decreased from $13.49 \%$ at $\mathrm{S} 1$ to $10.92 \%$ at S3 and disappeared at S4. Besides, the co-localized regions for MRL, SFW and LAG contribution to the phenotypic variance also showed similar temporal changes. Generally, our results revealed that the genetic architecture of the five seedling characteristics shows dynamic temporal changes during growth and development.

\section{Pleiotropy or linkage of QTLs}

We found here that many QTLs controlling multiple seedling characteristics were located at the same or overlapping marker interval on some chromosomes. This implied an existence of pleiotropic QTL or tightly linked QTL in our study. Xu et al. [7] suggested that if two QTL peaks are located very close to each other, and the 1-LOD support intervals completely or mostly overlapped, these two QTLs would be regarded as a single QTL having pleiotropic effect. In the present study, we delimited 1.5-LOD support intervals to confirm whether these two QTLs controlling multiple seedling characteristics can be identified as the pleiotropic QTL or tightly linked QTL. Based on this assumption, we found ten regions on chromosomes $2 \mathrm{H}, 3 \mathrm{H}$ and $7 \mathrm{H}$ that showed pleiotropic or tightly linkage effects on different seedling characteristics (Table 3).

Five regions on chromosome $2 \mathrm{H}$ were observed to simultaneously affect multiple seedling characteristics. Of these, a significant region with pleiotropic or tightly linkage effects on SFW, SLFW, SLDW, MRN, SELW, FILA, SELA and FOLA was close to both the SNP marker, 2HL_34260490 and the morphological marker, Vrs 1 (Fig. 3C; Table 3). The Vrs1 locus (controlling row type) has a pleiotropic effect on multiple traits [34, 61-63]. For example, Marquez-Cedillo et al. [61] and Wang et al. [34] reported that the Vrs1 locus had a pleiotropic effect on thousand grain weight, spike length, plant height, spikelet number on main spike and grain number per plant. Furthermore, some malting quality traits, such as grain-protein-percentage, diastatic power and soluble/ total protein ratio, were also coincident with the Vrs1 locus reported by Marquez-Cedillo et al. [62]. Sato et al. [63] suggested that the fusarium head blight (FHB) resistance QTL in Vrs 1 locus reported in two-row $\times$ six-row crosses might be pleiotropic effect of $V r s 1$ locus. Our study also showed a possible pleiotropic effect of the Vrs 1 locus and provided evidence to further support previous suggestions.

On chromosome $3 \mathrm{H}$ and $7 \mathrm{H}$, we also found that some regions showed pleiotropic effects on different seedling characteristics (Table 3). A pleiotropic QTL or tightly linked QTL, detected between SNP marker 3HL_29995337 and 3HL_32354397 near the SSR marker Bmag13, was related to $\mathrm{SH}$ and SELA. Examining the $3 \mathrm{H}$ linkage maps of Xue et al. [64] and GrainGenes3.0 (http://wheat.pw.usda.gov/GG3/) revealed that the marker bPb-6504 is near to the marker Bmag13, indicating that this QTL is likely the same to the $q S P L 3 c$ associated with spikes per line. In the previous studies using the same DH population, QTL for heading date (Qhd3-13), culm length (Qcl3-13), two internode length(Qitw3-13) and three internode length (Qith313), as reported by Ren et al. [49, 51], and QTLs for stomatal conductance (qGs3-13) and transpiration rate $(q \operatorname{Tr} 3$ 13) reported by Liu et al. [33] were also near this region (Additional file 3: Figure S3). A QTL located at 93/94 cM on chromosome $7 \mathrm{H}$ showed that pleiotropic or tightly linkage effects on THLL, SELA and THLA is likely the same to the QTL ( $q R W C 7-9)$ for relative water content and QTL (qSPD7-9) for relative chlorophyll content, as reported by Liu et al. [33]. These results provided favorable support for pleiotropic QTL or tightly linked QTL identified in our study. Further, this pleiotropic QTL or tightly linked QTL may be used for marker-assisted selection (MAS) and genetic improvement of barley seedling characteristics in barley breeding.

The phenomenon of pleiotropic effect or linked for QTLs universally exists in various crop genomes. Pleiotropic effects of genetic loci are thought to play a critical role in evolution, reflecting functional and developmental relationships among phenotypes [65]. The application of linked QTL and pleiotropic QTL for breeding purposes should be carried out with care, especially if the pleiotropy and linkage are in negative direction [7]. For 
example, the Huadamai 6 alleles with the pleiotropic QTL or tightly linked QTL on chromosome $3 \mathrm{H}$ increased main roots number but decreased maximum root length (Table 3). However, a pleiotropic QTL with opposite effects on the different traits complicated its application in barley improvement.

\section{QTL clusters in the genome}

In our study, we found that most of QTLs were located on chromosomes $2 \mathrm{H}, 3 \mathrm{H}$ and $7 \mathrm{H}$ (Figs. 2 and 3a). It is noteworthy that many QTLs gathered in the same chromosome regions, even for the unrelated traits (Table 5). For instance, one QTL cluster region for RDW, SLDW, MRL, SFW and RFW was mapped on chromosome $2 \mathrm{H}$ close to the marker GBM1218. Liu et al. [33] reported QTL clusters for physiological and morphological traits of flag leaf (net photosynthetic rate, stomatal conductance, flag leaf area, flag leaf length, flag leaf width, relative chlorophyll content and leaf nitrogen concentration) in the similar region. Similarly, Ren et al. [49] detected QTLs for heading date traits in this region. Wang et al. [34] also detected QTLs for spikelet number on main spike in this region. Considering all information here, we suggested that this region may be a credible region for cluster of QTLs.

The most important QTL cluster was detected on chromosome $2 \mathrm{H}$ close to the morphological marker Vrs1, which was clustered with 22 QTLs (31.43\%) for LAG, SH, MRL, MRN, SFW, SLFW, SLDW, RFW, RDW, FOLL, SELW, FILA, SELA and FOLA with contribution of 12.05\%-32.39\% (Table 5; Fig. 2). Wang et al.

Table 5 Putative QTL clusters on linkage groups in barley

\begin{tabular}{|c|c|c|c|c|}
\hline Num. ${ }^{a}$ & Chr. $^{b}$ & Involved QTLs ${ }^{c}$ & Interval & Position $(\mathrm{cM})^{\mathrm{d}}$ \\
\hline $\mathrm{C} 1$ & $2 \mathrm{H}$ & $\begin{array}{l}\text { LAG(S2, S3), FILA, } \\
\text { FILL, SELA }\end{array}$ & $\begin{array}{l}\text { 2HL_18227895- } \\
\text { 2_598509820 }\end{array}$ & $173.0 \pm 11.03$ \\
\hline C2 & $2 \mathrm{H}$ & $\begin{array}{l}\text { SH(S1, S2, S3, S4), } \\
\text { SFW(S1, S2, S3, S4), } \\
\text { LAG(S4), MRL(S3, S4), } \\
\text { MRN(S1, S2), SLDW(S4), } \\
\text { SLFW(S4), RFW(S4), } \\
\text { RDW(S4), FOLL, SELW, } \\
\text { FILA, SELA, FOLA }\end{array}$ & $\begin{array}{l}\text { 2_456666117- } \\
\text { 2_544135082 }\end{array}$ & $129.0 \pm 10.19$ \\
\hline $\mathrm{C} 3$ & $2 \mathrm{H}$ & $\begin{array}{l}\text { RDW(S4), SLDW(S4), } \\
\text { MRL(S3, S4), SFW } \\
(\text { S3, S4), RFW(S4) }\end{array}$ & $\begin{array}{l}\text { 2HS_30524211- } \\
\text { M_223185_603 }\end{array}$ & $68.8 \pm 10.18$ \\
\hline C4 & $3 \mathrm{H}$ & $\begin{array}{l}\text { FILA, FILL, SH } \\
(\mathrm{S} 1, \mathrm{~S} 2, \mathrm{~S} 3), \mathrm{SELA}\end{array}$ & $\begin{array}{l}\text { 3HL_42780152- } \\
\text { 3HL_32354397 }\end{array}$ & $25.6 \pm 6.74$ \\
\hline $\mathrm{C} 5$ & $7 \mathrm{H}$ & $\begin{array}{l}\text { FILA, SELA, THLL, } \\
\text { THLA, FILL, SFW(S1) }\end{array}$ & $\begin{array}{l}\text { 7HL_37824340- } \\
\text { 7_431414178 }\end{array}$ & $92.9 \pm 5.19$ \\
\hline C6 & $7 \mathrm{H}$ & $\begin{array}{l}\text { SELA, SH(S1, S3, S4), } \\
\text { FOLA, LAG(S1) }\end{array}$ & $\begin{array}{l}\text { 1H_82374297- } \\
7 \_348795436\end{array}$ & $117.4 \pm 9.83$ \\
\hline
\end{tabular}

${ }^{\mathrm{a}}$ The number of QTL clusters

${ }^{\mathrm{b}}$ Chromosome

'QTL was represented by the trait names, and the QTL detected by the corresponding stage were shown in brackets

${ }^{\mathrm{d}}$ The first figure indicated the distance from the top of the corresponding chromosome, and the second indicated the interval length
[34] reported QTL clusters for some agronomic traits (spikelet number on main spike, grain number per spike, spikelet number per plant, grain number per plant, grain weight per plant and thousand grain weight) in this chromosome region. Hori et al. [66] detected QTLs for plant height, spike exsertion length and thousand-kernel weight in this region. In addition, QTLs for spike number, floret number, grain number and hundred grain weight were also detected in this region by Chutimanitsakun et al. [67]. QTLs for seedling traits in this region may be a result of the pleiotropic effect of the Vrs 1 locus or expression of the closely linked genes for Vrs1.

Another significant QTL cluster underlying LAG, FILL, FILA and SELA was detected on chromosome $2 \mathrm{H}$ between SNP marker 2HL_18227895 and 2_598509820 (Table 5; Fig. 2). The effects from Huadamai 6 were positive for LAG, but negative for FILL, FILA and SELA. Castro et al. [68] detected QTLs for photoperiod response in this region. Wang et al. [34] also detected QTLs for length of main spike, spike density, thousand grain weight and grain weight per spike in this region, and suggested that the SNP marker 2_598509820 in this region could be used for marker-assisted selection. In addition, another three QTL clusters were obtained on chromosome $3 \mathrm{H}$ and $7 \mathrm{H}$, all of which enhanced development of stem-and-leaf traits (Table 5; Fig. 2).

QTL clustering in barley was repeatedly reported in some studies [33, 34, 56, 69]. In our study, we demonstrated several significant QTL clusters of seedling characteristics in barley under hydroponic culture. The genetic mechanism for this widespread phenomenon may be a linkage of genes and of pleiotropic effect of a single QTL in the same genomic region [70, 71]. However, whether it is linkage or pleiotropy, further research using fine mapping and cloning of QTLs or genes are needed validation.

\section{Conclusions}

In this research, a number of genomic regions containing many seedling-related QTLs involved in different traits and diverse seedling growth stages were detected. The two parents used for mapping population construction are different in row types (six-rowed dwarfing barley cultivar Huaai 11 and two-rowed barley cultivar Huadamai 6). We found that chromosome $2 \mathrm{H}$ close to the morphological marker Vrs1 contained the most important QTL cluster regions controlling multiple seedling characteristics. Some QTLs detected in this research could be used as a potential target for marker-assisted selection (MAS) in barley breeding.

\section{Methods}

Plant materials and hydroponic culture experiments The barley double haploid (DH) population used in the current study was derived by anther culture from a cross 
between Huaai 11 and Huadamai 6 in our research group. This population consisted of $122 \mathrm{DH}$ lines, have been described in our previous studies [33, 34, 49-52]. In the present study, 122 lines and the two parental cultivars were evaluated at seedling stage using the hydroponic culture (Fig. 1a). The experiment was conducted in greenhouse during the year 2014-2015 at the College of Plant Science and Technology of Huazhong Agricultural University, Wuhan, China. The conditions of greenhouse were set for $25 / 15{ }^{\circ} \mathrm{C}$ during a 16/8 h light/dark cycle, a photon flux density of $300 \mu \mathrm{mol} \mathrm{m} \mathrm{m}^{-2} \mathrm{~s}^{-1}$ during the $16 \mathrm{~h}$ light period, and relative humidity of $65 \%$ for $24 \mathrm{~h}$. Barley seeds of the two parents and 122 lines were surface sterilized for $15 \mathrm{~min}$ in a 5\% solution of sodium hypochlorite, rinsed thoroughly with distilled water, soaked in deionised water for $2 \mathrm{~h}$, and then germinated for 5 days on plastic board floating over the deionized water at room temperature. After 5 days, 6 uniform seedlings from each line were selected for transplanting into foam board (polystyrene) suspended in the plastic tanks (34 cm $\times 25 \mathrm{~cm} \times 12 \mathrm{~cm}$, length $\times$ width $\times$ height) with nutrient solution. Each seedling was anchored to holes $1.5 \mathrm{~cm}$ diameter in foam board with sterilized sponge. Each foam board had 5 rows of holes, and each row had 6 holes for a total of 30 seedlings per board. The distance between two seedlings was $3.6 \mathrm{~cm}$ (between rows) and $4.0 \mathrm{~cm}$ (within a row), respectively. Each tank contained eight liters of revised Hoagland's nutrient solution [72], which was renewed every seventh day to prevent nutrient exhaustion. When renewed the nutrient solution, each tank moves randomly to ensure that same environmental conditions. The solution $\mathrm{PH}$ was adjusted to $6.5 \mathrm{using}$ diluted $\mathrm{NaOH}$ and $\mathrm{HCl}$ before refreshing. The two parents and DH lines were grown in completely randomized design with six replicates. In each replication, one seedling was used for data collection.

\section{Phenotyping of seedling characteristics}

The phenotypes measured included leaf age (LAG), seedling height $(\mathrm{SH}, \mathrm{cm})$, maximum root length (MRL, $\mathrm{cm})$, main roots number (MRN) and seedling fresh weight (SWF, g) at four growth stages (13th, 20th, 27th and 34th days after germination) on the same six seedlings for each line. Root fresh weight (RFW, g), stemand-leaf fresh weight (SLFW, g), root dry weight (RDW, g) and stem-and-leaf dry weight (SLDW, g) were only measured at the 34th day after germination. For convenience, we used S1, S2, S3 and S4 to represent the 13th, 20th, 27th and 34th day after germination, respectively. In addition, leaf length (LL, $\mathrm{cm}$ ), leaf width (LW, $\mathrm{cm})$ and leaf area $\left(\mathrm{LA}, \mathrm{cm}^{2}\right)$ were measured in four leaves according to the leaf order of seedling. LL was measured for first leaf length (FILL, cm), second leaf length (SELL, cm), third leaf length (THLL, $\mathrm{cm}$ ) and fourth leaf length (FOLL, cm). LW was measured for first leaf width (FILW, cm), second leaf width (SELW, $\mathrm{cm}$ ), third leaf width (THLW, $\mathrm{cm}$ ) and fourth leaf width (FOLW, cm). LA as measured for first leaf area (FILA, $\mathrm{cm}^{2}$ ), second leaf area (SELA, $\mathrm{cm}^{2}$ ), third leaf area (THLA, $\mathrm{cm}^{2}$ ) and fourth leaf area (FOLA, $\mathrm{cm}^{2}$ ). The methods of measurement are listed in Table 6 .

\section{Statistical analysis}

The mean phenotypic values of the 21 seedling characteristics obtained from hydroponic culture were subjected to

Table $\mathbf{6}$ List of 21 quantitative traits investigated in the hydroponic experiment

\begin{tabular}{lll}
\hline Abbr. & Traits & Measurement standard \\
\hline LAG & Leaf age & Number of leaves grown with time ${ }^{\text {a }}$ \\
SH & Shoot height & Length of the seedling from basis to the tip of the longest leaf blade \\
MRL & Maximum root length & Length of the longest root from crown to root tip \\
MRN & Main root number & Number of primary root \\
SFW & Seedling fresh weight & Seedling weight after dry surface water \\
SLFW & Stem-and-leaf fresh weight & Stem-and-leaf weight after dry surface water \\
RFW & Root fresh weight & Root weight after dry surface water \\
SLDW & Stem-and-leaf dry weight & Stem-and-leaf weight after 2 days of drying at $75^{\circ} \mathrm{C}$ \\
RDW & Root dry weight & Root weight after 2 days of drying at $75^{\circ} \mathrm{C}$ \\
$L^{b}{ }^{\circ}$ & Leaf length & Length of the completely unfolded leaf from leaf basis to tip \\
$L^{c}$ & Leaf width & Maximum width of the completely unfolded leaf \\
$L^{d}$ & Leaf area & LA $=(L L \times L W) \times 0.83$ \\
\hline
\end{tabular}

${ }^{a}$ The roll-leaf length measurement standard is, if the length of roll-leaf less than $1 / 3$ the length of next leaf was recorded as 0.1 , between $1 / 3$ and $1 / 2$ the length of next leaf was recorded as 0.3 , between $1 / 2$ and $3 / 4$ the length of next leaf was recorded as 0.5 , between $3 / 4$ and the length of next leaf was recorded as 0.7 , longer than the length of next leaf was recorded as 0.9

${ }^{\mathrm{b}}$ The leaf length was measured including the first leaf length (FILL), second leaf length (SELL), third leaf length (THLL) and fourth leaf length (FOLL)

'The leaf width was measured including the first leaf width (FILW), second leaf width (SELW), third leaf width (THLW) and fourth leaf width (FOLW)

${ }^{\mathrm{d}}$ The leaf area was measured including the first leaf area (FILA), second leaf area (SELA), third leaf area (THLA) and fourth leaf area (FOLA) 
statistical analysis. Normality of distribution was tested using the method of Shapiro-Wilk. The descriptive statistics analyses were performed using SPSS programs (IBM SPSS Statistics, Chicago, IL, USA, http://www.ibm.com/ analytics/us/en/technology/spss). The heritability was estimated [73]. Frequency distribution and QTL-likelihood maps for the seedling characteristics were drawn using the Origin programs (OriginLab, Northampton, MA, USA, http://www.originlab.com). $P$-value higher than 0.05 was deemed as significance level.

\section{QTL analysis}

The high-density genetic linkage map constructed by Ren et al. [50] for the 'Huaai $11 \times$ Huadamai 6' population was used in the QTL analysis, which contains 1894 SNP markers and 68 SSR markers, covering all 7 chromosomes and spanning $1375.80 \mathrm{cM}$ of the barley genome with an average marker distance of $0.7 \mathrm{cM}$. The estimates of QTL positions and effects were determined by inclusive composite interval mapping (ICIM) [74] using the software QTL IciMapping 4.1 [75]. The mapping method was selected ICIM-ADD (additive effects) in 'BIP (QTL mapping in biparental populations)' function to analyze each trait from a single environment. Significant LOD (likelihood-of-odd) threshold for declaring a QTL of each trait was determined by 1000 permutations test with a Type 1 error of 0.05 [76]. The scanning step size was set at 1.0 centimorgan $(\mathrm{cM})$ and the probability in stepwise regression (PIN) was 0.001 . The rule recommended by Liu et al. [33] was used to name the QTLs, which were mapped on linkage groups using the software MapChart 2.2 [77]. The QTLs whose percentage of phenotypic variation explained (PVE) exceeded 20\%, were considered as major QTL, and otherwise minor QTL. If the 1.5-LOD support interval of two QTLs overlapped, these two QTL would be defined as co-localized QTLs. However, we independently counted each QTL to clearly specify the number of detected QTLs. Graingenes website (http://wheat.pw.usda.gov/GG3/) was used to compare the maker information.

\section{Additional files}

Additional file 1: Figure S1. Frequency distribution of 21 seedling characteristics in $\mathrm{DH}$ population. $P$ value of Shapiro-Wilk test for each stage was shown, the hypothesis of normal distribution was accepted when $P>0.05$ (significant at $P=0.05$ ), and the trend lines of the accepted normal distribution were shown. Trait abbreviations refer to the Table 6. S1 to S4 represented the 13th, 20th, 27th and 34th day after germination, respectively. (JPEG 5396 kb)

Additional file 2: Figure S2. QTL likelihood map for 17 seedling characteristics in the $\mathrm{DH}$ population grown under hydroponic culture conditions using inclusive composite interval mapping. Genetic maps (all chromosomes together) of barley linkage groups were shown in the abscissa and LOD scores of each trait in the ordinate. The significant LOD threshold was determined to be 3.0 by 1000 permutations test. Trait abbreviations refer to the Table 6.51 to 54 represented the 13th, 20th, 27 th and 34th day after germination, respectively. (JPEG $4454 \mathrm{~kb}$ )
Additional file 3: Figure S3. QTL locations for previous studies and current studies detected in the Huaai $11 \times$ Huadamai $6 \mathrm{DH}$ population. QTLs were mapped to chromosomes using peak position and nearest marker. (JPEG $4137 \mathrm{~kb}$ )

\section{Abbreviations}

cM: Centimorgan; DH: Double haploid; FILA: First leaf area; FILL: First leaf length; FILW: First leaf width; FOLA: Fourth leaf area; FOLL: Fourth leaf length; FOLW: Fourth leaf width; ICIM: Inclusive composite interval mapping; LOD: Likelihood of odd; MAS: Marker assisted selection; QTL: Quantitative trait locus; S1: 13th day after germination; S2: 20th day after germination; S3: 27th day after germination; S4: 34th day after germination; SELA: Second leaf area; SELL: Second leaf length; SELW: Second leaf width; SNP: Single nucleotide polymorphism; SSR: Simple sequence repeat; THLA: Third leaf area; THLL: Third leaf length; THLW: Third leaf width

\section{Acknowledgements}

None.

\section{Funding}

This project was supported by the earmarked fund for China Agriculture Research System (CARS-5).

\section{Availability of data and materials}

All relevant datasets supporting the conclusions of this article are available within the article and its additional files.

\section{Authors' contributions}

QW performed this study, statistical analysis and manuscript writing. XR, JW and BD assisted in phenotyping and software analysis. DS and GS conceived this study, coordinated the experiments, and wrote the manuscript. CL produced the Huaai 11 and Huadamai $6 \mathrm{DH}$ population. All authors read and approved the final version of the paper.

\section{Ethics approval and consent to participate}

Our research did not involve any human subjects, human material, or human data. All our studies have been performed in accordance with ethics

committee polices. The hydroponic culture experiment in greenhouse at the College of Plant Science and Technology of Huazhong Agricultural had been allowed and not involved private interests.

\section{Consent for publication}

Not applicable.

\section{Competing interests}

The authors declare that they have no competing interests.

\section{Publisher's Note}

Springer Nature remains neutral with regard to jurisdictional claims in published maps and institutional affiliations.

\section{Author details}

${ }^{1}$ College of Plant Science and Technology, Huazhong Agricultural University, Wuhan 430070, China. Biology Department, Saint Mary's University, 923 Robie Street, Halifax, NS B3H 3C3, Canada. 'Department of Agriculture \& Food/Agricultural Research Western Australia, 3 Baron-Hay Court, South Perth, WA 6155, Australia. ${ }^{4}$ Hubei Collaborative Innovation Center for Grain Industry, Jingzhou, Hubei 434025, China.

Received: 15 March 2017 Accepted: 30 October 2017

Published online: 07 November 2017

References

1. Qin D, Dong J, Xu F, Guo G, Ge S, Xu Q, et al. Characterization and fine mapping of a novel barley stage green-revertible albino gene (HvSGRA) by bulked Segregant analysis based on SSR assay and specific length amplified fragment sequencing. BMC Genomics. 2015;16:838.

2. Heneen WK. Cytogenetics and molecular Cytogenetics of barley: a model cereal crop with a large genome. In: Ullrich SE, editor. Barley: production, improvement, and uses. UK: Wiley-Blackwell; 2011. p. 112-21. 
3. Sbei H, Sato K, Shehzad T, Harrabi M, Okuno K. Detection of QTLs for salt tolerance in Asian barley (Hordeum vulgare L.) by association analysis with SNP markers. Breed Sci. 2014;64:378-88.

4. HTT V, Nguyen HTT, Tran KD, Khuat TH, Nakamura C. Genetic diversity of Vietnamese lowland rice germplasms as revealed by SSR markers in relation to seedling vigour under submergence. Biotechnol Biotechnol Equip. 2016; 30:17-25.

5. Kan G, Ning L, Li Y, Hu Z, Zhang W, He X, et al. Identification of novel loci for salt stress at the seed germination stage in soybean. Breed Sci. 2016;66: 530-41.

6. Nguyen TCT, Obermeier C, Friedt W, Abrams SR, Snowdon RJ. Disruption of germination and seedling development in Brassica napus by mutations causing severe seed hormonal imbalance. Front Plant Sci. 2016;7:322.

7. CG X, Li XQ, Xue Y, Huang YW, Gao J, Xing YZ. Comparison of quantitative trait loci controlling seedling characteristics at two seedling stages using rice recombinant inbred lines. Theor Appl Genet. 2004;109:640-7.

8. Bertholdsson NO. Early vigour and allelopathy-two useful traits for enhanced barley and wheat competitiveness against weeds. Weed Res. 2005;45:94-102.

9. Colmer TD, Munns R, Flowers TJ. Improving salt tolerance of wheat and barley: future prospects. Aust J Exp Agric. 2006:45:1425-43.

10. Abdulrahmani B, Ghassemi-Golezani K, Valizadeh M, Feizi-Asl V. Seed priming and seedling establishment of barley (Hordeum vulgare L.). J Food Agric Environ. 2007;5:179-84.

11. López-Castañeda C, Richards RA, Farquhar GD, Williamson RE. Seed and seedling characteristics contributing to variation in early vigor among temperate cereals. Crop Sci. 1996;36:1257-66.

12. Liao MT, Fillery IRP, Palta JA. Early vigorous growth is a major factor influencing nitrogen uptake in wheat. Funct Plant Biol. 2004:31:121-9.

13. Bertholdsson NO, Brantestam AK. A century of Nordic barley breedingeffects on early vigour root and shoot growth, straw length, harvest index and grain weight. Eur J Agron. 2009;30:266-74.

14. Ellis $\mathrm{RH}$. Seed and seedling vigour in relation to crop growth and yield. Plant Growth Regul. 1992;11:249-55.

15. Song W, Wang B, Hauck AL, Dong X, Li J, Lai J. Genetic dissection of maize seedling root system architecture traits using an ultra-high density bin-map and a recombinant inbred line population. J Integr Plant Biol. 2016;58:266-79.

16. Atkinson JA, Wingen LU, Griffiths M, Pound MP, Gaju O, Foulkes MJ, et al. Phenotyping pipeline reveals major seedling root growth QTL in hexaploid wheat. J Exp Bot. 2015;66:2283-92.

17. Tuberosa R, Sanguineti MC, Landi P, Giuliani MM, Salvi S, Conti S. Identification of QTLs for root characteristics in maize grown in hydroponics and analysis of their overlap with QTLs for grain yield in the field at two water regimes. Plant Mol Biol. 2002;48:697-712.

18. Kumar B, Abdel-Ghani AH, Pace J, Reyes-Matamoros J, Hochholdinger F, Lübberstedt T. Association analysis of single nucleotide polymorphisms in candidate genes with root traits in maize (Zea mays L.) seedlings. Plant Sci. 2014;224:9-19.

19. Wang $H, X u X$, Zhan $X$, Zhai $R$, Wu W, Shen $X$, et al. Identification of $q R L 7$, a major quantitative trait locus associated with rice root length in hydroponic conditions. Breed Sci. 2013;63:267-74.

20. Gamuyao R, Chin JH, Pariasca-Tanaka J, Pesaresi P, Catausan S, Dalid C, et al. The protein kinase Pstol1 from traditional rice confers tolerance of phosphorus deficiency. Nature. 2012:488:535-9.

21. Syed MA, Iftekharuddaula KM, Mian MAK, Rasul MG, Rahmam GKMM, Panaullah GM, et al. Main effect QTLs associated with arsenic phyto-toxicity tolerance at seedling stage in rice (Oryza sativa L.). Euphytica. 2016;209:805-14.

22. Burton AL, Johnson JM, Foerster JM, Hirsch CN, Buell CR, Hanlon MT, et al. QTL mapping and phenotypic variation for root architectural traits in maize (Zea mays L.). Theor Appl Genet. 2014;127:2293-311.

23. Abdel-Ghani AH, Kumar B, Reyes-Matamoros J, Gonzalez-Portilla PJ, Jansen C, Martin JPS, et al. Genotypic variation and relationships between seedling and adult plant traits in maize (Zea mays L.) inbred lines grown under contrasting nitrogen levels. Euphytica. 2013;189:123-33.

24. Liu X, Li R, Chang X, Jing R, Mapping QTL. For seedling root traits in a doubled haploid wheat population under different water regimes. Euphytica. 2013;189:51-66.

25. Kabir MR, Liu G, Guan P, Wang F, Khan AA, Ni Z, et al. Mapping QTLs associated with root traits using two different populations in wheat (Triticum aestivum L.). Euphytica. 2015;206:175-90.
26. Ellis RP, Forster BP, Gordon DC, Handley LL, Keith RP, Lawrence P, et al. Phenotype/genotype associations for yield and salt tolerance in a barley mapping population segregating for two dwarfing genes. J Exp Bot. 2002; 53:1163-76.

27. Bertholdsson NO, Holefors A, Macaulay M, Crespo-Herrera LAQTL. For chlorophyll fluorescence of barley plants grown at low oxygen concentration in hydroponics to simulate waterlogging. Euphytica. 2015;201:357-65.

28. Bertholdsson NO. Screening for barley waterlogging tolerance in nordic barley cultivars (Hordeum vulgare L.) using chlorophyll fluorescence on hydroponically-grown plants. Agronomy. 2013;3:376-90.

29. Xu R, Wang J, Li C, Johnson P, Lu C, Zhou MA. Single locus is responsible for salinity tolerance in a chinese landrace barley (Hordeum vulgare L.). PLoS One. 2012:7:e43079.

30. Hoffmann A, Maurer A, Pillen K. Detection of nitrogen deficiency QTL in juvenile wild barley introgression lines growing in a hydroponic system. BMC Genet. 2012;13:88.

31. González AM, Yuste-Lisbona FJ, Rodiño AP, Ron AMD, Capel C, GarcíaAlcázar M, et al. Uncovering the genetic architecture of Colletotrichum lindemuthianum resistance through QTL mapping and epistatic interaction analysis in common bean. Front Plant Sci. 2015;6:141.

32. Paterson AH, Lander ES, Hewitt JD, Peterson S, Lincoln SE, Tanksley SD. Resolution of quantitative traits into Mendelian factors by using a complete linkage map of restriction fragment length polymorphisms. Nature. 1988; 335:721-6.

33. Liu L, Sun G, Ren X, Li C, Sun D. Identification of QTL underlying physiological and morphological traits of flag leaf in barley. BMC Genet. 2015;16:29.

34. Wang J, Sun G, Ren X, Li C, Liu L, Wang Q, et al. QTL underlying some agronomic traits in barley detected by SNP markers. BMC Genet. 2016;17:103.

35. Zhou G, Panozzo J, Zhang XQ, Cakir M, Harasymow S, Li C. QTL mapping reveals genetic architectures of malting quality between Australian and Canadian malting barley (Hordeum vulgare L.). Mol Breed. 2016;36:70.

36. Li JZ, Huang XQ, Heinrichs F, Ganal MW, Röder MS. Analysis of QTLs for yield components, agronomic traits, and disease resistance in an advanced backcross population of spring barley. Genome. 2006;49:454-66.

37. Xue DW, Zhou MX, Zhang XQ, Chen S, Wei K, Zeng FR, et al. Identification of QTLs for yield and yield components of barley under different growth conditions. J Zheijang Univ Sci B. 2010;11:169-76.

38. Szücs P, Blake VC, Bhat PR, Chao S, Close TJ, Cuesta-Marcos A, et al. An integrated resource for barley linkage map and malting quality QTL alignment. The Plant Genome. 2009;2:134-40.

39. Panozzo JF, Eckermann PJ, Mather DE, Moody DB, Black CK, Collins HM, et al. QTL analysis of malting quality traits in two barley populations. Aust J Agric Res. 2007;58:858-66.

40. Ahmadi-Ochtapeh H, Soltanloo H, Ramezanpour SS, Naghavi MR, Nikkhah HR, Rad SY. QTL mapping for salt tolerance in barley at seedling growth stage. Biol Plantarum. 2015:59:283-90.

41. Siahsar BA, Narouei M. Mapping QTLs of physiological traits associated with salt tolerance in 'Steptoe' $\times$ 'Morex'doubled haploid lines of barley at seedling stage. J Food Agr Environ. 2010;88:751-9.

42. Broughton S, Zhou G, Teakle NL, Matsuda R, Zhou M, O'Leary RA, et al. Waterlogging tolerance is associated with root porosity in barley (Hordeum vulgare L.). Mol Breed. 2015;35:27.

43. Chen G, Krugman T, Fahima T, Chen K, Hu Y, Röder M, et al. Chromosomal regions controlling seedling drought resistance in Israeli wild barley, Hordeum spontaneum C. Koch. Genet Resour Crop Evol. 2010;57:85-99.

44. Asseng S, Turner NC, Botwright T, Condon AG. Evaluating the impact of a trait for increased specific leaf area on wheat yields using a crop simulation model. Agron J. 2003;95:10-9.

45. Nicola S. Understanding root systems to improve seedling quality. HortTechnology. 1998:8:544-9.

46. Arifuzzaman M, Sayed MA, Muzammil S, Pillen K, Schumann H, Naz AA, et al. Detection and validation of novel QTL for shoot and root traits in barley (Hordeum vulgare L.). Mol Breed. 2014;34:1373-87.

47. Songsri $P$, Jogloy $S$, Holbrook CC, Kesmala T, Vorasoot N, Akkasaeng C, et al. Association of root, specific leaf area and SPAD chlorophyll meter reading to water use efficiency of peanut under different available soil water. Agric Water Manag. 2009:96:790-8.

48. Sabiel SA, Huang S, Hu X, Ren X, Fu C, Peng J, et al. SNP-based association analysis for seedling traits in durum wheat (Triticum turgidum L. durum (Desf.)). Breed Sci. 2017;67:83-94. 
49. Ren X, Sun D, Sun G, Li C, Dong W. Molecular detection of QTL for agronomic and quality traits in a doubled haploid barley population. Aust J Crop Sci. 2013;7: 878-86.

50. Ren X, Wang J, Liu L, Sun G, Li C, Luo H, et al. SNP-based high density genetic map and mapping of btwd1 dwarfing gene in barley. Sci Rep. 2016; 6:31741.

51. Ren X, Sun D, Dong W, Sun G, Li C. Molecular detection of QTL controlling plant height components in a doubled haploid barley population. Genet Mol Res. 2014;13:3089-99.

52. Ren X, Sun D, Guan W, Sun G, Li C. Inheritance and identification of molecular markers associated with a novel dwarfing gene in barley. BMC Genet. 2010;11:89.

53. Arifuzzaman M, Günal S, Bungartz A, Muzammil S, Afsharyan NP, Léon J, et al. Genetic mapping reveals broader role of $\mathrm{Vrn}-\mathrm{H} 3$ gene in root and shoot development beyond heading in barley. PLoS One. 2016;11:e0158718.

54. Naz AA, Arifuzzaman M, Muzammil S, Pillen K, Léon J. Wild barley introgression lines revealed novel QTL alleles for root and related shoot traits in the cultivated barley (Hordeum vulgare L.). BMC Genet. 2014;15:107.

55. Reinert S, Kortz A, Léon J, Naz AA. Genome-wide association mapping in the global diversity set reveals new QTL controlling root system and related shoot variation in barley. Front Plant Sci. 2016;7:1061.

56. Schmalenbach I, Pillen K. Detection and verification of malting quality QTLs using wild barley introgression lines. Theor Appl Genet. 2009;118:1411-27.

57. WR W, Li WM, Tang DZ, HR L, Worland AJ. Time-related mapping of quantitative trait loci underlying tiller number in rice. Genetics. 1999;151:297-303.

58. Mansour E, Casas AM, Gracia MP, Molina-Cano JL, Moralejo M, Cattivelli L, et al. Quantitative trait loci for agronomic traits in an elite barley population for Mediterranean conditions. Mol Breed. 2014;33:249-65.

59. Qu Y, Mu P, Zhang H, Chen CY, Gao Y, Tian Y, et al. Mapping QTLs of root morphological traits at different growth stages in rice. Genetica. 2008;133: 187-200.

60. Price AH, Steele KA, Moore BJ, Jones RGW. Upland rice grown in soil-filled chambers and exposed to contrasting water-deficit regimes: II. Mapping quantitative trait loci for root morphology and distribution. Field Crops Res. 2002:76:25-43.

61. Marquez-Cedillo LA, Hayes PM, Kleinhofs A, Legge WG, Rossnagel BG, Sato $\mathrm{K}$, et al. QTL analysis of agronomic traits in barley based on the doubled haploid progeny of two elite north American varieties representing different germplasm groups. Theor Appl Genet. 2001;103:625-37.

62. Marquez-Cedillo LA, Hayes PM, Jones BL, Kleinhofs A, Legge WG, Rossnagel BG, et al. QTL analysis of malting quality in barley based on the doubledhaploid progeny of two elite north American varieties representing different germplasm groups. Theor Appl Genet. 2000;101:173-84.

63. Sato K, Hori K, Takeda K. Detection of Fusarium head blight resistance QTLS using five populations of top-cross progeny derived from two-row $\times$ tworow crosses in barley. Mol Breed. 2008;22:517-26.

64. Xue D, Huang Y, Zhang X, Kang W, Westcott S, Li C, et al. Identification of QTLs associated with salinity tolerance at late growth stage in barley. Euphytica. 2009;169:187-96

65. Ehrich TH, Vaughn TT, Koreishi SF, Linsey RB, Pletscher LS, Cheverud JM Pleiotropic effects on mandibular morphology I. Developmental morphological integration and differential dominance. J Exp Zool B Mol Dev Evol. 2003;296:58-79.

66. Hori K, Kobayashi T, Shimizu A, Sato K, Takeda K, Kawasaki S. Efficient construction of high-density linkage map and its application to QTL analysis in barley. Theor Appl Genet. 2003:107:806-13.

67. Chutimanitsakun Y, Nipper RW, Cuesta-Marcos A, Cistué L, Corey A, Filichkina T, et al. Construction and application for QTL analysis of a restriction site associated DNA (RAD) linkage map in barley. BMC Genomics. 2011;12:4

68. Castro AJ, Hayes P, Viega L, Vales I. Transgressive segregation for phenological traits in barley explained by two major QTL alleles with additivity. Plant Breed. 2008:127:561-8.

69. Hori K, Sato K, Takeda K. Detection of seed dormancy QTL in multiple mapping populations derived from crosses involving novel barley germplasm. Theor Appl Genet. 2007;115:869-76.

70. Peng J, Ronin Y, Fahima T, Röder MS, Li Y, Nevo E, et al. Domestication quantitative trait loci in Triticum dicoccoides, the progenitor of wheat. Proc Natl Acad Sci U S A. 2003;100:2489-94.

71. Wang H, Huang C, Guo H, Li X, Zhao W, Dai B, et al. QTL mapping for fiber and yield traits in upland cotton under multiple environments. PLoS One. 2015;10:e0130742.
72. Hoagland DR, Arnon DI. The water-culture method for growing plants without soil. Calif Agric Exp Stat Circ. 1950;347:1-32.

73. Hanson C, Robinson H, Comstock R. Biometrical studies of yield in segregating populations of Korean lespedeza. Agron J. 1956;48:268-72.

74. Li H, Ye G, Wang JA. Modified algorithm for the improvement of composite interval mapping. Genetics. 2007;175:361-74.

75. Meng L, Li H, Zhang L, Wang J. QTL IciMapping: integrated software for genetic linkage map construction and quantitative trait locus mapping in biparental populations. The Crop J. 2015;3:269-83.

76. Churchill GA, Doerge RW. Empirical threshold values for quantitative trait mapping. Genetics. 1994;138:963-71.

77. Voorrips RE. MapChart: software for the graphical presentation of linkage maps and QTLs. J Hered. 2002;93:77-8.

\section{Submit your next manuscript to BioMed Central and we will help you at every step:}

- We accept pre-submission inquiries

- Our selector tool helps you to find the most relevant journal

- We provide round the clock customer support

- Convenient online submission

- Thorough peer review

- Inclusion in PubMed and all major indexing services

- Maximum visibility for your research

Submit your manuscript at www.biomedcentral.com/submit
Biomed Central 